\title{
Índices de preço para o transporte de cargas: o caso da soja
}

Augusto Hauber Gameiro Professor da Universidade de São Paulo José Vicente Caixeta-Filho Professor da Universidade de São Paulo

\section{Palauras-chave}

índice, preço, transporte.

Classificação JEL C02, Q13, R40

Key words

index, price, transportation.

JEL Classification C02, Q13, $\mathrm{R} 40$.

\section{Resumo}

Esta pesquisa objetivou analisar metodologias para elaboração de índices de preços para o transporte de cargas. O estudo das principais fórmulas da Teoria Econômica culminou com a conclusão que os Índices de Fisher e Walsh são aqueles capazes de atender ao maior número de preceitos lógicos, estatísticos e econômicos. Em seguida, surgem os índices geométricos de Törnqvist, Vartia e Theil. Os Índices de Laspeyres e Paasche, apesar de apresentarem algumas limitações, acabam sendo amplamente utilizados, graças a maior capacidade de operacionalização. A pesquisa apresentou um estudo de caso para o transporte da soja em grão. Foram realizados quatro tratamentos. Obteve-se a variação acumulada no nível geral de preços para o transporte rodoviário de soja no Brasil, no período entre fevereiro de 1998 e março de 2002. De acordo com os resultados, essa variação acumulada teria sido de $76 \%$.

\section{Abstract}

The purpose of this research is to analyze methodologies for calculation of price indexes for cargo freight in Brazil. The study on the most used mathematical formulas has come to the conclusion that Fisher and Walsh indexes are those which comply with most of the logical, statistical and economic principles, followed by geometric indexes, such as Törnqvist, Vartia and Theil. Laspeyres and Paasche, in spite of their limitations, are widely used in practical terms. A case study was selected to evaluate variations on possible procedures for index construction. Four treatments have been conducted. As a result, we observed that the accumulated variation of the general price level for road transportation of soybean in Brazil between February 1998 and March 2002 was $76 \%$. 


\section{1_Introdução}

Esta pesquisa foi motivada pela necessidade de desenvolvimento de metodologias para cálculo de índices de preços para o transporte de cargas no Brasil, em especial as de origem agrícola. Essas respondem pelo maior volume de movimentação no País, além de serem caracterizadas por significativa oscilação nos preços de seus fretes.

Os produtos agroindustriais apresentam baixo valor relativo por unidade de peso ou volume. Por outro lado, as regiões produtoras e as consumidoras muitas vezes são distantes umas das outras. Conjuntamente, esses fatores conferem custos significativos à distribuição dos produtos. ${ }^{1} \mathrm{~A}$ flutuação de seus preços, decorrente das características sazonais dos cultivos, é outro aspecto que deve ser considerado. Em períodos de colheita, há uma concentração na oferta, acompanhada de redução nos preços relativos e maior necessidade de escoamento da produção. Esse contexto implica aumento na demanda por serviço de transporte, que tende a ter seu preço elevado. Portanto, tem-se a combinação de preço baixo da carga com preço elevado do transporte. Essa é a principal característica da logística agroindustrial.

A utilização de índices de preços sempre recebeu destaque na Ciência Eco- nômica. O desafio consiste em sua formulação representar adequadamente os fenômenos socioeconômicos reais.

A pesquisa aqui apresentada inseriu, além dos fundamentos teóricos, um estudo de caso do transporte rodoviário da soja a granel no Brasil. A importância desse produto para a agricultura brasileira foi o principal motivo que levou à sua escolha. Caixeta-Filho e Gameiro (2001) afirmam que há intensa utilização dos serviços de transporte no escoamento da safra da soja, provocando grande desestabilização no mercado de fretes rodoviários no Brasil.

Indicadores relacionados aos serviços de transportes podem apresentar várias utilidades, tanto para funções administrativas de uma firma, visando a um auxílio na tomada de decisões específicas, quanto no âmbito macroeconômico, para nortear políticas públicas e privadas. Alguns são elaborados por instituições de interesse público, como universidades e bolsas de negócios; outros são construídos por empresas privadas com algum interesse nesse tipo de informação. Essas iniciativas são relevantes no sentido de proporcionar ideias para a elaboração de novos índices a serem propostos. Na Tabela 1, são ilustrados os índices de fretes encontrados na literatura ou no meio de negócios (web).

\footnotetext{
Segundo Caixeta-Filho e Gameiro (2001), no Brasil o preço do frete rodoviário apresenta significativa participação no valor da carga, dependendo do produto e da época. No caso do milho, por exemplo, o preço do frete pode chegar a mais de $30 \%$ do valor em condições extremas. No caso da soja, um dos produtos mais importantes da agricultura brasileira, o frete representa, em média, 13\% do valor do produto.
} 
Tabela 1 Índices de fretes identificados

\begin{tabular}{|c|c|c|c|c|c|}
\hline Índice & Elaboração & Objetivo & Modal & $\begin{array}{c}\text { Freqüência } \\
\text { (publicação) }\end{array}$ & Fórmula \\
\hline CPI & \multirow{2}{*}{$\begin{array}{c}\text { Bureau of } \\
\text { Labor Statistics }\end{array}$} & \multirow{2}{*}{$\begin{array}{c}\text { Mensurar o desempenho } \\
\text { do serviço de transporte } \\
\text { nos EUA }\end{array}$} & Passageiros urbanos & Mensal & \multirow{2}{*}{$\begin{array}{l}\text { Laspeyres com } \\
\text { ponderação fixa }\end{array}$} \\
\hline RFI & & & Ferroviário & Mensal & \\
\hline CECFI & \multirow{2}{*}{$\begin{array}{l}\text { Shanghai Shipping } \\
\text { Exchange }\end{array}$} & \multirow{2}{*}{$\begin{array}{c}\text { Ser referência para a tomada } \\
\text { de decisões comerciais } \\
\text { e políticas }\end{array}$} & $\begin{array}{c}\text { Marítimo } \\
\text { (contêineres) }\end{array}$ & \multirow{2}{*}{ Semanal } & \multirow{2}{*}{ Laspeyres } \\
\hline CCBFI & & & $\begin{array}{c}\text { Marítimo } \\
\text { (cabotagem) }\end{array}$ & & \\
\hline $\begin{array}{c}\mathrm{INCT}_{\mathrm{A}}, \mathrm{INCT}_{\mathrm{R}}, \\
\mathrm{INCT}_{\mathrm{CE}}\end{array}$ & FIPE/NTC & $\begin{array}{c}\text { Ser indicador do custo } \\
\text { do transporte rodoviário } \\
\text { no Brasil }\end{array}$ & Rodoviário & Mensal & Laspeyres \\
\hline ICTU & FIPE/SPTrans & $\begin{array}{l}\text { Medir a variação do custo } \\
\text { do transporte em São Paulo }\end{array}$ & Coletivo urbano & Mensal & Paasche \\
\hline Sifreca & ESALQ/USP & $\begin{array}{c}\text { Divulgar preços médios mensais } \\
\text { do frete de produtos agrícolas } \\
\text { e agroindustriais }\end{array}$ & $\begin{array}{c}\text { Rodoviário, ferroviário, } \\
\text { hidroviário (fluvial e cabotagem), } \\
\text { marítimo e aeroviário }\end{array}$ & Mensal & $\begin{array}{l}\text { Média } \\
\text { aritmética }\end{array}$ \\
\hline $\begin{array}{l}\text { Índices do Báltico } \\
\text { (BFI, BPI, etc.) }\end{array}$ & Baltic Exchange & $\begin{array}{c}\text { Ser referência de mercado } \\
\text { e para balizamento em mercados } \\
\text { futuros e derivativos }\end{array}$ & Marítimo & Diário & Laspeyres \\
\hline VIFES & $\begin{array}{c}\text { Cass Information } \\
\text { Systems }\end{array}$ & $\begin{array}{l}\text { Medir volume físico } \\
\text { e financeiro dos embarques } \\
\text { dos clientes do CIS }\end{array}$ & Todos & Mensal & $\begin{array}{c}\text { Não } \\
\text { identificada }\end{array}$ \\
\hline ITFIL & $\begin{array}{l}\text { Não } \\
\text { identificada }\end{array}$ & $\begin{array}{c}\text { Atender à demanda de traders } \\
\text { de petróleo e outros interessados } \\
\text { em contratos futuros }\end{array}$ & Marítimo & $\begin{array}{l}\text { Não } \\
\text { identificada }\end{array}$ & $\begin{array}{l}\text { Não } \\
\text { identificada }\end{array}$ \\
\hline IRFI & $\begin{array}{l}\text { Transport Corporation } \\
\text { of India }\end{array}$ & $\begin{array}{l}\text { Suprir falta de informações } \\
\text { e reduzir sensibilidade } \\
\text { dos preços a flutuações }\end{array}$ & Rodoviário & Semanal & $\begin{array}{l}\text { Média } \\
\text { aritmética }\end{array}$ \\
\hline
\end{tabular}

Observa-se que o método Laspeyres é amplamente o mais utilizado. Ademais, a maior parte é formada de índices cujas rotas são, além de pouco numerosas, bem definidas, o que permite um processo de amostra- gem menos complexo. A periodicidade dos índices varia de diária a mensal e está diretamente relacionada à liquidez dos respectivos mercados e aos objetivos dos índices. Especificamente para o transporte rodoviário 
de cargas, tem-se o INCT/FIPE, com um propósito bastante interessante de mensurar a evolução dos custos do transporte.

Destaca-se, finalmente, a participação de empresas privadas na elaboração dos índices. Essas empresas podem ser corretoras de transporte, bolsas de negócios ou mesmo os agentes transportadores. Essa diversidade ressalta o papel que os índices de transporte apresentam à sociedade, uma vez que há todos esses esforços em sua utilização.

Este artigo está assim organizado: é apresentada uma revisão sobre os números-índice, abordando-se os enfoques teóricos e as principais fórmulas utilizadas. $\mathrm{Na}$ sequência, apresenta-se a metodologia proposta para a análise dos índices de transporte. Segue-se com os resultados da aplicação da metodologia sobre uma base de dados real e as respectivas conclusões.

\section{2_ Teoria dos Índices de Preço}

A escolha da fórmula de cálculo deve estar relacionada à concepção teórica para construção dos índices. Para Carmo (1987):

O cerne dessas dificuldades reside no fato de que um indice é aplicado, quando se trata de um complexo de itens heterogêneos, a magnitudes não observáveis diretamente, como o nivel geral de preços, o nivel de utilidade ou o nivel de atividade econômica.
Refere-se, assim, à medida de variações na magnitude não observável, entre duas on mais situacões (p. 22).

O problema não está apenas na mensuração de magnitudes não observáveis, mas também - e de certa forma decorrente disso - na necessidade de agregação de itens heterogêneos.

Portanto, pode haver uma distância entre teoria e aplicação prática no que se refere à elaboração dos números-índice, em especial os de preço. Isso porque as diversas fórmulas desenvolvidas originam índices que são apenas "aproximações" da realidade, ou seja, medidas que se aproximam da real magnitude não observada. Tem-se, por conseguinte, a necessidade de aproximação ou enfoques, o que levou a diversos estudos nesse sentido.

A seguir são abordados os principais enfoques utilizados na construção dos índices de preço, a saber: i) enfoque axiomático; ii) enfoque estatístico; e iii) enfoque econômico.

\section{1_Enfoque axiomático}

O enfoque axiomático, ou também chamado de "lógico-matemático", tem sua fundamentação na análise matemática das fórmulas de cálculo. Foi Irving Fisher o grande defensor e um dos precursores dessa concepção. Fisher analisava cada 
2 A representação

matemática dos testes

mencionados consta em

Gameiro (2003). uma das possíveis fórmulas para o cálculo dos índices, submetendo-as a uma série de testes ${ }^{2}$ que tinham sua sustentação baseada na lógica.

Os principais testes propostos por Fisher (1927) eram os denominados "testes de reversão", e os que recebiam mais destaque eram os de: (i) reversão de commodity ("the commodity reversal test"); (ii) reversão do tempo ("the time reversal test"); e (iii) reversão de fator ("the factor reversal test"). Ao primeiro, o autor designou o termo "preliminar", e os outros dois foram designados teste 1 e 2 , respectivamente.

O primeiro teste acabou sendo chamado de "preliminar" por ser facilmente atendido. $\mathrm{O}$ índice de preço deve ser invariável à permuta dos produtos que o compõe.

Já o atendimento ao teste de reversão ao tempo não é trivial. $\mathrm{O}$ teste, apesar de amplamente divulgado e defendido por Fisher, foi proposto inicialmente por Pierson (1896). Esse teste apresenta relação direta com a definição de base de cálculo. Dado que um índice representa a variação entre dois pontos, é necessário que haja uma base de comparação, que geralmente é um ponto no tempo. O presente teste garante que um índice, que meça a variação da base para o ponto referencial (forward), apresente - exatamente - o resultado inverso caso seja calculado do ponto referencial para a base (backward). Apesar da relevância do teste, ele não é atendido por uma série de índices de larga utilização, como os de Laspeyres e Paasche, por exemplo, que serão descritos nos próximos parágrafos. Facilmente pode-se observar que índices baseados em médias aritméticas não atendem ao teste, ao contrário daqueles baseados em médias geométricas. Esse foi um dos motivos que estimularam o uso das médias geométricas. Posteriormente, percebeu-se que essas, porém, apresentavam outras inconveniências, como será abordado no enfoque estatístico.

$\mathrm{O}$ terceiro teste de reversão de Fisher - o de reversão de fator - é bastante análogo ao anterior. Assim como a fórmula deve permitir o intercâmbio entre os dois períodos de cálculo, também deveria possibilitar a troca entre preços e quantidades sem gerar diferenças. Em outras palavras, o resultado da multiplicação de preços por quantidades deveria sempre dar o mesmo valor. Ao apresentar esse teste, ficou clara a existência de um índice de preços sempre vinculado a um índice de quantidades.

O Índice de Fisher - que também será apresentado oportunamente - é um dos poucos que atendem a esse teste, sendo esse um dos motivos que levaram o autor a denominá-lo de "índice ideal". Os Índices de Laspeyres e Paasche não aten- 
dem ao teste. Entretanto, por ser um teste polêmico, essa acaba não sendo uma limitação a eles (Diewert, 2001). Os índices geométricos, que atendiam ao Teste 1 de Fisher, não o fazem em relação ao Teste 2 , prejudicando sua recomendação sob essa ótica.

O quarto teste de Fisher é o da circularidade, estudado pela primeira vez por Westergaard em 1890. Provavelmente esse é o teste que gera maior polêmica. Partindo do mesmo raciocínio do teste de reversão ao tempo, definido para dois pontos, Fisher questionou se não seria o caso de haver uma fórmula que garantisse a consistência do índice quando calculado entre mais de dois pontos no tempo ou no espaço. Com seus estudos, Fisher acabou concluindo por ser equivocada a comparação do teste da circularidade com o de reversão ao tempo. Mais do que isso, conclui que o atendimento ao teste da circularidade é exatamente uma prova de que a fórmula em questão é equivocada, quando da consideração de um índice baseado em mais de um produto (Diewert, 2001).

Um importante assunto na Teoria dos Números-Índice está por trás do teste da circularidade. Trata-se da escolha da base, que pode ser fixa ou encadeada. Para um índice qualquer apresentar o mesmo resultado independentemente do tipo de base adotada (fixa ou encadeada), ele precisa atender ao teste em questão. Diewert (2001) explica que Funke et al. (1979) demonstraram que o teste da circularidade só seria atendido pelo índice geométrico de Jevons. O problema por trás do Índice de Jevons é que esse considera o peso dos preços constantes e, portanto, independentes da quantidade consumida dos produtos em cada ponto no tempo. Esse é o principal motivo que descaracteriza o índice como um bom estimador da variação geral dos preços. Por esse motivo, o teste da circularidade - como afirmava Fisher - não é uma exigência para um "bom" índice de preço. Contudo, Diewert (2001) explica que, apesar de não ser plenamente atendido, é interessante que o resultado do teste aproxime-se ao seu atendimento. $\mathrm{O}$ próprio Índice de Fisher, conforme por ele mesmo demonstrado, apresenta um "desvio bastante pequeno" em relação ao resultado esperado do teste. Além desse, os Índices de Walsh e Törnqvist também apresentam resultados com pequenos desvios em relação ao teste da circularidade.

Os quatro testes apresentados são considerados os precursores do enfoque axiomático. Depois desses, uma série de outros foram propostos e, paulatinamente, passaram a fazer parte do conjunto de testes recomendados. $\mathrm{O}$ autor contemporâneo que tem se preocupado na sistematização dos testes é W. Erwin Diewert. Em seu 
" 3 Na sua sistematização de 1986, Diewert incluiu esse teste denominando-o de "teste da invariância a mudanças na escala". Segundo o autor, o teste teria sido sugerido por Vartia para o estudo do mercado de moeda. Não fica claro o motivo de ter sido excluído por Diewert em sua sistematização de 2001. Provavelmente isso possa ter ocorrido por se tratar de um teste específico para a circulação de moeda. trabalho de 2001, ele apresenta uma completa revisão e descrição dos testes utilizados na teoria dos índices de preço. As contribuições de Diewert iniciaram em meados na década de 1970. Entre as principais que foram consultadas para a realização desta pesquisa, destacam-se: Diewert (1976, 1978, 1981, 1987, 1988, 2001 e 2004). Recentemente, seus trabalhos Diewert et al. (2009), Diewert e Hill (2009) e Diewert (2009) vem consolidando sua posição de destaque no tratamento dos índices de preço.

A sistematização dos testes de Diewert (2001) - contemplando 20 dos testes apresentados - é apenas uma das formas de conceber o enfoque axiomático. Outros autores sistematizaram os distintos índices de modo alternativo, sendo dois exemplos os trabalhos de Eichhorn e Voeller (1978) e Vartia (1976).

Melo (1982), que é uma das principais referências brasileiras no assunto, utilizou a sistematização proposta pelos autores mencionados, agregando outras contribuições. Nessa sistematização, a abordagem axiomática não se baseia apenas nos chamados "testes", mas agrega as propriedades dos índices em axiomas, propriedades decorrentes e propriedades desejadas. A sistematização alternativa consta, inicialmente, de cinco axiomas, descritos a seguir (entre parênteses, o nome correspondente na sis- tematização de Diewert): Axioma da Monotonicidade (incluindo os testes de monotonicidade em preços correntes e em preços da base); Axioma da Homogeneidade Linear (teste da proporcionalidade nos preços correntes); Axioma da Identidade (teste básico da identidade, ou de preços constantes); Axioma da Dimensionalidade (não estabelecido por Diewert) ${ }^{3}$; e Axioma da Comensurabilidade (teste da "comensurabilidade"). Esses axiomas seriam os "requisitos mínimos" necessários para que um índice de preços pudesse ser considerado como tal.

As propriedades decorrentes, por sua vez, derivam do atendimento dos axiomas. Essas são em número de três, a saber: proporcionalidade (testes de proporcionalidade nos preços correntes); homogeneidade de grau menos um (teste da proporcionalidade inversa dos preços no período da base); e valor médio (teste do valor médio para preços).

Finalmente, as propriedades desejadas seriam aquelas cujo atendimento daria a um índice o título de "índice superior", denominação essa bastante utilizada (ver, por exemplo, van Veelen e van der Weide, 2008). As propriedades desejadas constam, basicamente, dos principais testes de Fisher, além de outros dois que serão apresentados a seguir. São elas as propriedades: re- 
versão temporal (teste de reversão do tempo); reversão de fatores (teste de reversão de fator); circularidade (de mesmo nome); determinação e consistência na agregação.
Para facilitar a compreensão dos testes comentados, os 20 testes da sistematização de Diewert (2001) são ilustrados na Tabela 2.

Tabela 2_Sistematização dos 20 testes axiomáticos

\begin{tabular}{|c|c|c|c|}
\hline \multirow{4}{*}{ "Básicos" } & Positividade & Eichhorn \& Voeller & Nenhuma \\
\hline & Continuidade & Fisher & Nenhuma \\
\hline & Identidade ou dos preços constantes & $\begin{array}{l}\text { Laspeyres, Walsh, Eichhorn } \\
\text { \& Voeller e Fisher }\end{array}$ & Alguma inconsistência com a Teoria Econômica \\
\hline & Cesta fixa ou das quantidades constantes & $\begin{array}{l}\text { Willard Fisher, Lowe, Scrope, } \\
\text { Jevons, etc. }\end{array}$ & Alguma inconsistência com a Teoria Econômica \\
\hline \multirow{4}{*}{$\begin{array}{l}\text { De homoge- } \\
\text { neidade }\end{array}$} & Proporcionalidade em preços correntes & Walsh, Eichhorn \& Voeller e Vogt & Nenhuma \\
\hline & Proporcionalidade inversa nos preços da base & Eichhorn \& Voeller & Nenhuma \\
\hline & $\begin{array}{c}\text { Invariância a mudanças proporcionais } \\
\text { nas quantidades correntes }\end{array}$ & Vogt & $\begin{array}{l}\text { Alguma inconsistência, pois exige a garantia } \\
\text { do teste de reversão de fator }\end{array}$ \\
\hline & $\begin{array}{l}\text { Invariância a mudanças proporcionais nas } \\
\text { quantidades da base }\end{array}$ & Diewert & $\begin{array}{l}\text { Alguma inconsistência, pois exige a garantia } \\
\text { do teste de reversão de fator }\end{array}$ \\
\hline \multirow{4}{*}{ Simétricos } & Reversão de commodity & Fisher e Walsh & Nenhuma \\
\hline & Reversão do tempo & Pierson, Walsh e Fisher & $\begin{array}{l}\text { Nenhuma. Os famosos índices de Laspeyres } \\
\text { e Paasche, porém, não o atendem }\end{array}$ \\
\hline & Reversão de quantidades & Funke \& Voeller & Alguma inconsistência com a Teoria Econômica \\
\hline & Reversão de preços & Diewert & Alguma inconsistência com a Teoria Econômica \\
\hline \multirow{3}{*}{$\begin{array}{l}\text { De valor } \\
\text { médio }\end{array}$} & Valor médio para preços & Eichhorn \& Voeller & Nenhuma \\
\hline & Valor médio para quantidades & Diewert & $\begin{array}{l}\text { Alguma inconsistência, pois exige a garantia } \\
\text { do teste de reversão de fator }\end{array}$ \\
\hline & Limite de Paasche e Laspeyres & Bowley e Fisher & $\begin{array}{l}\text { Alguma inconsistência, dependendo } \\
\text { do enfoque econômico }\end{array}$ \\
\hline \multirow[b]{3}{*}{$\begin{array}{l}\text { De monoto- } \\
\text { nicidade }\end{array}$} & Em preços correntes & Eichhorn \& Voeller & Nenhuma \\
\hline & Em preços da base & Eichhorn \& Voeller & Nenhuma \\
\hline & Em quantidades correntes & Vogt & $\begin{array}{l}\text { Alguma inconsistência, pois exige a garantia } \\
\text { do teste de reversão de fator }\end{array}$ \\
\hline
\end{tabular}

Fonte: Gameiro (2003), adaptado de Diewert (2001). 
$\mathrm{O}$ autor sistematizou esses testes tendo como propósito organizar os testes atendidos pelo "Índice Ideal de Fisher". No entanto, há alguns outros testes que também receberam atenção dos estudiosos. Esses tantos testes são sistematizados na Tabela 3 .

À luz dessas informações, pode-se concluir que não há um índice que atenda a todos os testes. Ou, por outro lado, há testes cuja aprovação pode não ser necessária em algumas situações. Cada teste poderá ter ou não relevância em contextos particulares dependendo dos objetivos designados aos índices. A sistematização dos testes é uma importante contribuição para o entendimento e a elaboração de qualquer índice de preço, de modo que não podem deixar de ser considerados.

\section{2_Enfoque estatístico}

O enfoque estatístico dos índices de preço, também denominado de "enfoque estocástico", tem nos trabalhos de Jevons (1879) o seu berço.

A ideia básica do enfoque estocástico é a de que cada preço relativo, $p_{n}^{1} / p_{n}^{0}$, para $n=1, \ldots, N$, pode ser considerado como uma estimativa comum da taxa de inflação entre os períodos 0 e 1 . Ao propor seu índice, imaginou que a inflação causava um aumento proporcional nos preços em geral: $\ln \left(p_{n}^{1} / p_{n}^{0}\right)=\beta+\varepsilon_{n} ; i=1, \ldots, N$. Seguindo as hipóteses de um modelo econométrico tradicional, o estimador de $\beta$ seria o logaritmo da média geométrica dos relativos de preços. Consequentemente, o estimador da taxa comum de inflação $\alpha$ seria o

Tabela 3_Sistematização de quatro testes axiomáticos de relevância

\begin{tabular}{|c|c|c|}
\hline Reversão de fator & Fisher & Muita. Diversos autores não o aceitam. \\
\hline Circularidade & Westergaard e Fisher & $\begin{array}{c}\text { Muita. Só é atendido em uma situação } \\
\text { especial inconsistente com a } \\
\text { Teoria Econômica. }\end{array}$ \\
\hline $\begin{array}{l}\text { Determinação } \\
\text { ("irrelevance of tiny commodities") }\end{array}$ & Diewert & $\begin{array}{l}\text { Alguma. Trata-se de um teste "opcional", } \\
\text { dependendo do objetivo do índice. }\end{array}$ \\
\hline Consistência na agregação & Theil & $\begin{array}{l}\text { Alguma. Trata-se de um teste "opcional", } \\
\text { dependendo do objetivo do índice. }\end{array}$ \\
\hline
\end{tabular}

Fonte: Gameiro (2003). 
Índice de Jevons. Esse índice, contudo, não é ponderado, sendo bastante limitado em relação à sua utilização prática. Keynes era o maior crítico dessa limitação.

Da iminente limitação, surgiram as iniciativas para a ponderação dos índices sobre o enfoque estatístico, tendo em Walsh seu precursor. Törnqvist também apresentou significativas contribuições. Deve-se a Theil, porém, os maiores subsídios teóricos nessa área.

Theil (1974) defendeu que uma fórmula de índice ponderado, e simétrico, poderia ser obtida pela afirmativa de que a probabilidade de que um produto seja consumido é igual à média aritmética das participações das despesas do produto nos períodos 0 e 1 . Com isso, obteve a fórmula que originou o índice que fora proposto inicialmente por Törnqvist, e que, por esse motivo, recebeu a denominação de "Índice de Törnqvist". Diewert (2001) explica que a ideia de Theil ao desenvolver o enfoque estatístico apresentou uma série de vantagens no entendimento de algumas fórmulas que vinham sendo utilizadas. Os Índices de Laspeyres e de Palgrave, por exemplo, sob algumas condições, podem ser vistos como casos especiais, derivados do enfoque estatístico, como foi demonstrado por Theil e está ilustrado em Diewert (2001).
O enfoque estatístico considera, no âmago da análise, a distribuição dos relativos de preços. Essa distribuição pode ser dos relativos diretamente (das quais Laspeyres e Palgrave são resultados específicos), como também dos seus logaritmos (o que gera Törnqvist) e ainda dos seus recíprocos (inversos), gerando os índices que acabaram ficando conhecidos como "harmônicos", como o Índice Harmônico-Laspeyres.

Faz-se pertinente ressaltar que o enfoque estatístico é, muitas vezes, compreendido de modo equivocado, levando a aplicações indevidas de algumas fórmulas. Já se comentou que Keynes, tendo como preocupação análises meramente monetárias, criticava a correta aplicação desse. O próprio Fisher (1927) foi enfático nesse sentido:

\section{In choosing the formula of an index num- ber the 'skewness' or asymmetry of the distribution of the terms averaged is of $a b$ - solutely no consequence (Fisher, p. 408).}

Frisch (1950), com seu trabalho clássico que provou a inconsistência do atendimento simultâneo aos testes de Fisher, também apresenta sua crítica ao enfoque. De modo interessante, Melo (1982) tratou com bastante propriedade a questão, comungando das ideias de Vartia (1976), quando diz que o enfoque apresentava apenas "interesse histórico". 


\footnotetext{
4 Sendo $p^{0}$ o preço de determinado produto no momento inicial; $p^{1}$ o preço desse produto no momento final; $q^{0}$ a quantidade comercializada no momento inicial, e $q^{1}$ a quantidade comercializada no momento final.

5 Esse trabalho é representado pela citação Konüs (1939), referente versão publicada no idioma inglês naquele ano, devidamente citada nas referências bibliográficas.
}

Os fundamentos por trás das críticas ao enfoque estatístico são bastante simples de ser compreendidos. Uma vez que os índices são agregados de preços e quantidades, trata-se de uma função $n$-dimensional, de modo que acaba não fazendo sentido um enfoque que considera apenas algumas dimensões. Por exemplo, o índice $P\left(p^{0}, p^{1}, q^{0}, q^{1}\right)^{4}$ apresenta quatro dimensões, uma para cada vetor, impedindo a segregação dessas para que a distribuição de probabilidades seja considerada.

Mesmo assim, a existência do enfoque estatístico não pode ser simplesmente desprezada. A construção de um índice, na maioria dos casos, insere a agregação de subíndices em níveis inferiores. Quando da consideração de estágios formados por preços de um produto específico - como será o caso empírico desenvolvido nesta pesquisa -, o estudo da sua distribuição é válido, de forma que o enfoque acaba tendo o seu papel.

\subsection{Enfoque econômico}

$\mathrm{O}$ enfoque econômico - à semelhança dos demais - surgiu da necessidade de elaboração de índices de custo de vida das pessoas, tendo, como fundamento, a Teoria Econômica do Consumidor. A característica central dessa concepção, e que a difere dos anteriores, é o entendimento de que preços e quantidades guar- dam forte relação entre si. As palavras de Carmo (1987) sintetizam adequadamente o propósito do enfoque econômico:

De fato, o que se busca com a aproximação econômica é a compatibilização de fórmulas de cálculo às especificações das funcões agregadas em cada caso - função utilidade, função de produção, funções custo e dispêndio unitário etc. (p. 36).

Diversos nomes surgem com relevância na construção do enfoque. Keynes foi um importante crítico dos enfoques axiomático e estatístico, o que acabou estimulando a busca por novos conhecimentos. Suas indagações partiam dos estudos da relação entre preço e volume de moeda.

$\mathrm{Na}$ Rússia, em 1924, ${ }^{5}$ A. A. Konüs publica seu trabalho "O problema do verdadeiro Índice do Custo de Vida", lançando as bases do enfoque econômico ao considerar a construção de um índice obedecendo à teorização do comportamento do ser humano como consumidor.

O economista francês François Divisia (1925) surge como uma das maiores contribuições teóricas para o estudo dos números-índice. Ao desenvolver a ideia dos "índices contínuos" como uma alternativa aos denominados "índices binários" ou "índices bissutuacionais", Divisia revolucionou a Teoria dos Índices de Preço. 
Ragnar Frisch, da Universidade de Oslo, Noruega, em 1936, lança uma importante contribuição à Teoria dos NúmerosÍndice, desmistificando - com embasamento científico - uma série de paradoxos na época. Um exemplo é a prova da inconsistência do sistema de testes de Fisher, da maneira como foi originalmente concebido. Também era outro crítico do enfoque estatístico. Frisch delimitou a avaliação dos índices em duas formas: critério atomístico e critério funcional. No primeiro, preços e quantidades eram vistos como "duas coleções de variáveis independentes"; no segundo, "[...] presume-se a existência de certas relações características entre preços e quantidades". Essa forma de entender as variáveis que formam os índices foi determinante na evolução da Teoria.

A interdependência entre as variáveis ficou clara na explicação de Diewert (2001) sobre a teoria de Konüs: dado um vetor de preços de produtos (ou insumos), que o agente se defronta em um dado período de tempo, assume-se que o correspondente vetor de quantidade observado é a solução para o problema de minimização de custo, problema esse que envolve tanto as funções de utilidade (ou preferência) do consumidor quanto a função de produção de um produtor.

\section{4_ As fórmulas de cálculo dos índices de preços}

Apresentados os enfoques relacionados à construção dos índices de preço, neste item são discutidos os principais índices existentes e suas características, especialmente relacionadas ao atendimento desses enfoques. Objetiva-se conhecer as fórmulas potenciais para o cálculo dos índices de preço de frete de interesse desta pesquisa.

Os índices foram sistematizados no Quadro 1 e são identificados pelo subscrito. Na sequência, os índices são discutidos. Para entendimento das fórmulas, considera-se a seguinte nomenclatura: $I_{\text {indicie }}$ o respectivo índice de preços do período $t$ (referência) em relação ao período $b$ (base); $N$ o número de bens (ou serviços); $p_{n}^{t}$ o preço do bem $n$ no período $t$; e $p_{n}^{b}$ o preço do mesmo bem no período $b$. Especificamente para o $I_{\text {Vartial }}, v_{n}^{t}$ é o valor do produto $n$ no período de referência $(t): v_{n}^{t}=p_{n}^{t} q_{n}^{t} ; v_{n}^{b}$ é o valor do produto $n$ no período base $(b)$ : $v_{n}^{b}=p_{n}^{b} q_{n}^{b} ; p_{n}^{t}$ é o preço do produto $n$ no período de referência $(t) ; p_{n}^{b}$ é o preço do produto $n$ no período base (b). Além disso, $\sum_{n=1}^{N} w_{n}^{t}=1 ; \sum_{n=1}^{N} w_{n}^{b}=1 ; V^{t}=\sum_{n=1}^{N} v_{n}^{t}$ $\mathrm{e} V^{b}=\sum_{n=1}^{N} v_{n}^{b}$.
6 Esse trabalho é representado pela referência Frisch (1950), que foi uma tradução para a Revista Brasileira de Estatística, conforme citação completa nas referências bibliográficas. 


\section{Quadro 1_Índices de preços considerados na pesquisa}

$$
\begin{gathered}
I_{\text {Carli }}=\frac{\sum_{n=1}^{N}\left(\frac{p_{n}^{t}}{p_{n}^{b}}\right)}{N} \\
I_{\text {Lowe }}=\frac{\sum_{n=1}^{N} p_{n}^{t} q_{n}}{\sum_{n=1}^{N} p_{n}^{b} q_{n}} \\
I_{\text {Dutot }}=\frac{\sum_{n=1}^{N} p_{n}^{t} / N^{N}}{\sum_{n=1}^{N} p_{n}^{b} / N} \\
I_{\text {LogPaasshe }}=\prod_{n=1}^{N}\left(\frac{p_{n}^{t}}{p_{n}^{b}}\right)^{w_{n}^{t}} \\
I_{\text {Cogpessall }}=\frac{\prod_{n=1}^{N}\left(\frac{p_{n}^{t}}{p_{n}^{b}}\right)^{\frac{1}{N}}}{\sum_{n=1}^{N}\left(\frac{p_{n}^{b}}{p_{n}^{t}}\right)^{N}}
\end{gathered}
$$$$
I_{\text {Wass } s b}=\frac{\sum_{n=1}^{N} p_{n}^{t}\left(q_{n}^{b} q_{n}^{t}\right)^{\frac{1}{2}}}{\sum_{n=1}^{N} p_{n}^{b}\left(q_{n}^{b} q_{n}^{t}\right)^{\frac{1}{2}}}
$$$$
I_{\text {HarLaspeyres }}=\frac{1}{\sum_{n=1}^{N} w_{n}^{b}\left(\frac{p_{n}^{b}}{p_{n}^{t}}\right)}
$$$$
I_{\text {Fisher }}=\sqrt{I_{\text {Laspeyres }} \times I_{\text {Paasche }}}
$$$$
I_{\text {Paasche }}=\frac{\sum_{n=1}^{N} p_{n}^{t} q_{n}^{t}}{\sum_{n=1}^{N} p_{n}^{b} q_{n}^{t}}=\frac{1}{\sum_{n=1}^{N} w_{n}^{t}\left(\frac{p_{n}^{b}}{p_{n}^{t}}\right)}
$$$$
\log I_{\text {Vartial }}=\sum_{n=1}^{N} \frac{\frac{v_{n}^{t}-v_{n}^{b}}{\sum_{n=1}^{N}\left(\log \frac{v_{n}^{t}}{v_{n}^{b}}\right)}}{\frac{V^{t}-V^{b}}{\log \left(\frac{V^{t}}{V^{b}}\right)} \log \left(\frac{p_{n}^{t}}{p_{n}^{b}}\right)}
$$$$
I_{\text {Laspeyres }}=\frac{\sum_{n=1}^{N} p_{n}^{t} q_{n}^{b}}{\sum_{n=1}^{N} p_{n}^{b} q_{n}^{b}}, \operatorname{com} w_{n}^{b}=\frac{p_{n}^{b} q_{n}^{b}}{\sum_{n=1}^{N} p_{n}^{b} q_{n}^{b}}
$$$$
I_{\text {Geometrico }}=\prod_{n=1}^{N}\left(\frac{p_{n}^{t}}{p_{n}^{b}}\right)^{\sum_{n=1}^{N} p_{n}^{b} q_{n}^{b}}=\prod_{n=1}^{N}\left(\frac{p_{n}^{t}}{p_{n}^{b}}\right)^{w_{n}^{b}}
$$$$
I_{\text {Palg rave }}=\sum_{n=1}^{N} w_{n}^{t}\left(\frac{p_{n}^{t}}{p_{n}^{b}}\right), \operatorname{com} w_{n}^{t}=\frac{p_{n}^{t} q_{n}^{t}}{\sum_{n=1}^{N} p_{n}^{t} q_{n}^{t}}
$$$$
\log I_{\text {Theil }}=\sum_{n=1}^{N} \frac{\left[w_{n}^{t} w_{n}^{b}\left(\frac{w_{n}^{t} w_{n}^{b}}{2}\right)\right]^{\frac{1}{3}}}{\sum_{n=1}^{N}\left[w_{n}^{t} w_{n}^{b}\left(\frac{w_{n}^{t} w_{n}^{b}}{2}\right)\right]^{\frac{1}{3}}} \log \left(\frac{p_{n}^{t}}{p_{n}^{b}}\right)
$$

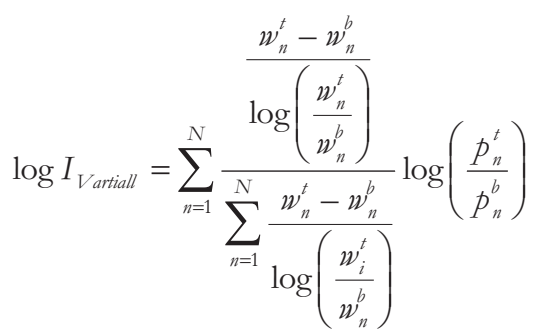

$I_{\text {Geometrico }}=\prod_{n=1}^{N}\left(\frac{p_{n}^{t}}{p_{n}^{b}}\right)_{n=1}^{\frac{p_{n}^{b} q_{n}^{b}}{\sum_{n}^{N} p_{n}^{b} q_{n}^{b}}}=\prod_{n=1}^{N}\left(\frac{p_{n}^{t}}{p_{n}^{b}}\right)^{w_{n}^{b}}$

$I_{\text {Palg rave }}=\sum_{n=1}^{N} w_{n}^{t}\left(\frac{p_{n}^{t}}{p_{n}^{b}}\right), \operatorname{com} w_{n}^{t}=\frac{p_{n}^{t} q_{n}^{t}}{\sum_{n=1}^{N} p_{n}^{t} q_{n}^{t}}$

$I_{\text {Tormqvist }}=\prod_{n=1}^{N}\left(\frac{p_{n}^{t}}{p_{n}^{b}}\right)^{\frac{p_{n=1}^{b} q_{n}^{b}}{\sum_{n}^{b} p_{n}^{b}}+\frac{p_{n}^{t} q_{n}^{t}}{\sum_{n=1}^{N} p_{n}^{t} q_{n}^{t}}}{ }^{2}=\prod_{n=1}^{N}\left(\frac{p_{n}^{t}}{p_{n}^{b}}\right)^{\frac{w_{n}^{b}+w_{n}^{t}}{2}}$ 
Carli (1764), segundo Walsh (1901), teria criado um dos primeiros índices de preço que se tem conhecimento, utilizando-se de uma média aritmética simples das razões dos preços nos respectivos períodos. Com essa fórmula, Carli estava criando o que Fisher (1927) passou a chamar de "preços relativos". O Índice de Carli apresenta uma série de limitações, uma vez que supõe que os preços evoluem a uma mesma taxa. Sob o que mais tarde seria chamado de "enfoque estatístico", o índice seria um adequado estimador da evolução dos preços, caso a hipótese imposta por esse enfoque fosse atendida. Entretanto, já é bastante consagrada a ideia de que os preços não evoluem a uma mesma taxa. Especificamente no caso dos fretes, a existência de custos fixos, que se diluem conforme aumenta o tempo/distância do transporte, é um indicativo bastante forte de que essa evolução, de fato, não deve ser constante. Uma análise mais detalhada das limitações desse índice pode ser encontrada em Gameiro (2003).

Em 1738, Dutot, citado por Diewert (1987), já teria utilizado uma fórmula matemática para obter um índice de preço dado pela razão entre a média geral dos preços em determinado período e a média dos preços no período-base. Esse passou a ser chamado - por sugestão também de Fisher (1927) - de "índice agregativo simples". Havia, entretanto, na metodologia, uma possibilidade de erro bastante grande em decorrência da diferença de magnitude dos produtos (e suas unidades), motivo pelo qual o Índice de Dutot não se disseminou.

Em 1812, Young inovou ao propor ponderações pelas quantidades produzidas. Teria sido uma das primeiras propostas de ponderação dos índices (Fisher, 1927). Com as guerras napoleônicas, a relação entre o aumento dos preços e o valor do dinheiro estimulou alguns estudantes a se preocupar com o fato. Exemplos que se destacaram foram Lowe e Scrope. O primeiro foi considerado por Kendall (1969) como o pai de um conceito muito importante: o de ponderação dos índices.

Outra importante contribuição relacionada à ponderação foi a do matemático Palgrave. Esse propôs a ponderação do preço relativo de cada produto pelo peso no mercado. Esse peso seria representado pelo valor do dispêndio incorrido com o produto sobre o dispêndio total realizado. As ideias precursoras de Lowe e Palgrave foram fundamentais para a inspiração de duas das fórmulas mais importantes e que ainda desempenham papel central na construção de índices de preços: Laspeyres (1871) e Paasche (1874). O Índice de Laspeyres mantém fixas as quantidades em uma cesta de bens 
7 Como será apresentado nos resultados, sugere-se que os Índices de Lowe, Laspeyres, Paasche, Fisher e Walsh sejam considerados como "derivados de Lowe", pela sua semelhança matemática. no período-base e observa como o custo total dessa cesta move-se ao longo do tempo até o período presente. O Índice de $\mathrm{Pa}$ asche, por sua vez, mantém fixas as quantidades no período presente (referencial) e determina como o custo total comportou-se nos períodos anteriores.

Uma importante limitação desses índices está no fato de não atenderem ao teste de reversão do tempo. Apesar dessa reconhecida limitação, a evolução da teoria acabou demonstrando que esses índices são bastante importantes. Isso pelo fato de que são passíveis de aplicações práticas e podem fornecer adequadas aproximações - ou pelo menos, fornecer os limites - para os supostos índices "verdadeiros". Os índices do grupo "derivados de Lowe" não atendem aos citados testes de circularidade, de reversão de fator e de preço. Também não atendem ao teste de reversão de quantidade, que garante que, se os vetores de quantidades forem trocados entre dois períodos, o índice de preço deve manter-se constante. Sob o ponto de vista estatístico, esses índices também têm sua sustentação teórica. Theil (1960), considerando os preços relativos distribuídos aleatoriamente, demonstrou que, se a probabilidade de despesa com cada produto no período-base é dada pela sua participação no mercado (o montante gasto com o produto sobre o total gasto), então naturalmente o Índice de Laspeyres seria uma fórmula de cálculo recomendada. Da mesma forma, se a probabilidade de cada produto a ser adquirido for dada pela participação relativa dos seus gastos no total durante o período referência, então se chegaria ao Índice de Paasche.

Sob o terceiro - e talvez o mais relevante - enfoque, o "econômico", Konüs (1939) demonstrou que os Índices de Laspeyres e Paasche seriam os limites do suposto verdadeiro índice, no caso de a função agregação estar sob as condições de maximização de utilidade e minimização do custo do consumidor.

A utilização de uma ou outra fórmula - de Laspeyres ou Paasche - sempre foi fonte de muitas discussões, tendo sido tratada inicialmente e com bastante propriedade por Fisher (1927), que acabou propondo uma fórmula mista de cálculo de índice. Esse índice acabou ficando conhecido como "Índice Ideal de Fisher". As ideias de Fisher (1927) baseavam-se no fato de que a fórmula de Laspeyres, por manter constantes as quantidades consumidas, superestimaria o índice real de evolução dos preços, uma vez que o princípio da Teoria do Consumidor - de que este migra para outros produtos à medida que os preços dos similares aumentam (sem sair da mesma curva de utilidade) - acabaria 
sendo violado. Por outro lado, o Índice de Paasche subestimaria a evolução dos preços, já que as quantidades do período final estariam ajustadas segundo a variação relativa dos preços dos bens substitutos/complementares durante o período. Sendo assim, a fórmula de Fisher, dada pela média geométrica dos dois índices, acaba por caracterizar um índice intermediário.

O Índice de Fisher, indubitavelmente, é um dos mais recomendados para a utilização como índice de preço. Isso se deve ao fato de que esse índice apresenta um adequado desempenho no que se refere ao atendimento dos testes axiomáticos, aproximando-se do que passou a ser chamado de "índice verdadeiro". O maior mérito do Índice de Fisher é responder ao teste da reversão de fator, que, por ser tão polêmico, não é considerado na sistematização de muitos autores, como Diewert (2001), por exemplo. O Índice de Fisher seria o único a ser aprovado em todos os 20 testes propostos por Diewert (2001), simultaneamente. O índice também atende ao teste da determinação.

O Índice de Fisher, porém, continua não sendo capaz de responder ao teste da circularidade. Apesar disso, o autor demonstrou que o resultado do índice era muito aproximado do que seria esperado de um índice que satisfizesse a esse teste ao aplicá-lo, empiricamente, sobre uma base real de da- dos. Fisher chegou a afirmar que o atendimento a esse teste seria uma prova da inconsistência da fórmula, ${ }^{8}$ como já mencionado.

No ano de 1998, uma edição especial do Journal of Economic Perspectives foi toda dedicada à discussão sobre a necessidade de revisão do Índice de Preços ao Consumidor nos Estados Unidos (Consumer Price Index - CPI), principal índice de custo de vida (índice de inflação) daquele país (ver, por exemplo, Persky, 1998).

Persky (1998, p. 198) escreve com propriedade: "[...] attempts to measure the level of prices can only produce chimerical quantifications of the unquantifiable". No fundo, ainda de acordo com o autor, o assunto que norteava a formação dos índices de preço não era nada mais do que o da mensuração do valor. Uma vez que a moeda serve como um meio de troca de bens, o preço da moeda era um ponto inicial óbvio para se estudar o valor. O problema central da teoria do valor, reconhecido por Adam Smith e alguns de seus sucessores, surgiria da observação de que o valor de troca da moeda flutua, por si só, consideravelmente.

John Stuart Mill, na metade do século XIX, chegou a negar a existência de qualquer mensuração geral de valor, uma vez que passou a analisar a moderna concepção de oferta e demanda. Para Persky (1998), os economistas neoclássicos que
8 Com o avanç do enfoque econômico, a tese de Fisher ganhou força, reduzindo a importância do teste da circularidade, que até mesmo foi excluído das exigências de muitos autores. Isso tudo ocorreu até que aparecesse a grande contribuição de Divisia (1925), economista que revolucionou a Teoria dos Índices de Preço ao desenvolver a ideia dos índices contínuos. 
seguiram Mill basearam suas teorias de valor de troca nos fundamentos das utilidades marginais.

Jevons (1879), ainda analisado por Persky (1998), chegou a afirmar que o valor de uma commodity, sob o ponto de vista neoclássico, não teria nenhuma importância se fosse visto independentemente das várias taxas que seriam trocadas umas pelas outras e, eventualmente, sugeriu o abandono do termo "valor". Em seu trabalho de 1865, propôs a utilização de um índice dessa natureza. A maior limitação do Índice de Jevons é o fato de que, assim como os precursores Carli e Dutot, trata-se de um índice não ponderado. Mas, apesar de pouco aplicável na prática, o Índice de Jevons deu importante contribuição à Teoria dos Números-Índice, sendo fundamental para o enfoque estatístico e para o estudo dos índices geométricos - como detalhado a seguir. Tal índice foi o único a atender ao teste da circularidade.

Marshall (1887), citado por Diewert (1987), mostrou preocupação semelhante no que se refere à medição do valor e sua variação. Para Persky (1998), ele endossou a busca pelo valor de troca da moeda e também forneceu sua grande contribuição com a construção de índices de cadeia (chain indexes).

Esses últimos parágrafos devem ter deixado transparecer a ideia de que um ín- dice de preço será sempre uma aproximação a um número que procura representar movimentos heterogêneos de preços de uma amostra. Ainda assim, ao longo do século $\mathrm{XX}$, os estudiosos seguiram buscando e propondo fórmulas alternativas de cálculo.

A evolução natural do Índice de Jevons foi o índice geométrico ponderado. A literatura, como ressalta Melo (1982), não atribui a aplicação precursora desse índice a nenhum autor, de modo que sua denominação ficou apenas "Índice Geométrico".

Mas a ponderação dos preços já foi suficiente para que o índice deixasse de atender ao teste da circularidade com exatidão. Então, concluiu-se que nenhum índice ponderado, ainda que geométrico, seria capaz de atender à circularidade. Mesmo assim, continuava a busca por índices que, então, gerassem resultados que, pelo menos, se aproximassem da circularidade. Dessa busca surgiram, entre outros, os Índices de Törnqvist e Walsh. Os índices geométricos em geral - incluindo o de Jevons, já comentado, e os de Törnqvist e Logarítimo-Paasche, tratados mais adiante - falham, contudo, no atendimento ao teste da determinação.

Deve-se considerar ainda os trabalhos de Walsh (1921). Apesar de a proposta ter partido de Fisher (1927), esse credita a Walsh a descoberta do "Índice de preços ideal de Fisher", já mencionada. Como os 
demais, apesar das inconsistências encontradas por ele próprio nas análises, Walsh, em seu texto de 1921, estudado por Diewert (1987), também criou sua fórmula de cálculo. O Índice de Walsh não passa em alguns testes axiomáticos, ainda que tenha forte apelo estatístico e econômico. Não atende a dois dos quatro testes de monotonicidade, nem aos testes de reversão de preço, do limite de Laspeyres e Paasche. Apresenta uma pequena superioridade axiomática em relação ao Índice de Törnqvist, que não satisfaz a nenhum dos testes de monotonicidade. O Índice de Walsh também não responde aos controversos testes da circularidade, de reversão de fator e de determinação.

É importante que se exponham as outras fórmulas de interesse para a Teoria dos Números-Índice. Fisher (1927), além de propor a amplamente difundida fórmula de cálculo do "Índice Ideal de Fisher", lançou mão dos diversos tipos de média que poderiam ser utilizadas para o cálculo dos índices, tais como a aritmética, a geométrica, a harmônica, etc. Por exemplo, tem-se a média harmônica simples dos preços relativos, utilizada por Coggeshall, em 1886. Já o exemplo de utilização da média geométrica, apresentado por Fisher (1927), foi a fórmula de Jevons. Há ainda outras duas fórmulas avaliadas por Fisher e que tive- ram alguma utilização prática no cálculo dos índices: Índice Logaritmo Paasche e Índice Harmônico Laspeyres. Apesar de nenhum autor levar o crédito desses índices, sua nomenclatura foi proposta por Vartia (1976).

Seguindo o histórico da proposição de fórmulas de cálculo, deve-se considerar ainda a importante contribuição de Törnqvist (Diewert, 1987 e 2001). Este índice, e também o de Theil (que são bastante semelhantes), apresentam várias limitações axiomáticas, não atendendo aos testes das quantidades constantes, de reversão de preço e de quantidade, do valor médio para quantidades, do limite de Laspeyres e Paasche, e aos quatro testes de monotonicidade. Ainda assim, do ponto de vista econômico, possuem forte recomendação de uso sob algumas condições. Diewert (2001) explica que, apesar de todas essas supostas limitações lógicas, quando aplicado a uma série normal de informações, o Índice de Törnqvist aproxima-se bastante do Índice de Fisher, gerando resultados muito próximos aos dos 20 testes atendidos por este último.

$\mathrm{Na}$ evolução da formulação dos índices, ainda se deve considerar dois autores que apresentaram significativas contribuições, conforme Melo (1982), a saber: Theil (1974) e Vartia (1976). O primeiro contribuiu no sentido de apresentar um suposto 
ajuste à fórmula de Törnqvist. Por sua vez, Vartia obteve sucesso ao propor duas fórmulas que satisfizessem um número maior de propriedades axiomáticas desejadas por Fisher, das quais uma delas atendeu a quatro das seis principais propriedades. Até então, os índices existentes satisfaziam a apenas três propriedades de Fisher. Em razão da complexidade de representação exponencial desses índices, utiliza-se a fórmula logarítmica para sua exposição. Os Índices de Vartia I e II, juntamente com o Índice de Fisher, são os únicos que passam nos polêmicos testes de reversão de fator e de determinação. Respondem também ao teste de reversão de tempo. Contudo, há alguns axiomas que não são respeitados por esses índices, especialmente os de reversão de preços e de quantidades, e os de monotonicidade.

Diante de todas as discussões teóricas acerca dos índices de preço, Persky (1998) afirma que:

As long as neoclassical economics rejects the comparison and aggregation of utility levels, it's not exactly clear what an aggregate price index can mean in neoclassical terms (p. 202).

Apesar do suposto vácuo teórico existente na explicação neoclássica para o fundamento de um índice, é inegável sua larga utilização e, consequentemente, sua utilidade para a sociedade como um todo.
Além disso, deve-se reforçar que grande parte das discussões teóricas advém da necessidade de mensuração do "custo de vida" pelos chamados "Índices de Preço ao Consumidor". Carmo (1987) escreveu:

A bistória da aplicação de números-indice à economia está estreitamente ligada à noção de indice de preços ao consumidor, como uma 'proxy' de variações no poder de compra da moeda (p. 15).

Para situações mais simples, como a mensuração do preço de um produto ou serviço específico, muitas das controvérsias perdem o sentido, dado que não se estaria mais diante do dilema da agregação de produtos e das utilidades individuais, tornandose, exclusivamente, mera medida matemática e estatística. Ainda assim, o problema da construção dos números-índice está diretamente relacionado ao da agregação de itens diferentes ou heterogêneos.

A exposição acerca das principais fórmulas, tendo como base os enfoques econômicos, estatísticos e lógicos, fornece uma ideia de quais seriam as mais adequadas sob cada um deles.

\section{3_Metodologia}

A relativa ambiguidade na elaboração de índices que mais aproximem a teoria da 
realidade implica necessidade de se testar empiricamente a capacidade de resposta quando aplicado a uma situação real.

A metodologia foi aplicada a uma base de dados existente. Foram utilizados os dados do Sistema de Informações de Fretes (Sifreca). ${ }^{9} \mathrm{O}$ transporte do produto "soja a granel" foi eleito como objeto de estudo. A soja é o produto agrícola de maior importância econômica para o Brasil.

O modelo econômico sob o qual está baseado o cálculo dos índices é o da formação do preço do frete, adaptado de Samuelson (1977). Segundo o modelo, há um transportador representativo maximizador de lucro, com livre mobilidade na prestação do serviço, portanto, podendo transportar soja de qualquer origem para qualquer destino do País.

\section{1_ Modelo de formação do preço do transporte}

O modelo de Samuelson (1977) parte do pressuposto de que a demanda por transporte é do tipo derivada. Em outras palavras, o serviço de transporte é "consumido" como parte do processo de produção de um bem qualquer. Dessa forma, a demanda pelo transporte é uma função da oferta e demanda da commodity transportada.

Há vários ofertantes de certa commodity no Ponto A que será vendida em outra localização. Portanto, enquanto o Ponto A tem, no agregado, o monopólio da oferta da commodity, os indivíduos ofertantes no Ponto A são perfeitamente competitivos. A função de oferta agregada para a commodity no Ponto A é $S(p)$, na qual $p$ é o preço recebido pelos ofertantes.

Similarmente, há vários compradores da commodity na localização representada pelo Ponto B. Enquanto o Ponto B tem, no agregado, o monopsônio do mercado da commodity, os indivíduos compradores são, da mesma forma que em A, considerados perfeitamente competitivos. A função de demanda agregada no Ponto B é $D(p+t+l(q))$, na qual $p$ é o preço de mercado da unidade da commodity no Ponto A; $t$ é a "tarifa de transporte" (preço do frete) para a unidade da commodity entre os Pontos A e B; e l(q) são os custos logísticos por unidade da commodity movimentada em uma carga de tamanho $q$. Assume-se que $l(q)$ é uma função única para todos os compradores e, portanto, a demanda agregada deve ser expressa como uma função de $p+t+l(q)$, o custo total que um comprador no Ponto $B$ incorre para consumir uma unidade da commodity considerada.

No primeiro caso, se o transportador tem o monopólio do frete dos produtos entre os dois pontos, esse transportador terá uma receita que será igual a $t D(p+t+l(q))$. $\cdots \cdots \cdots \cdots$

Projeto desenvolvido pelo

Departamento de Economia,

Administração e Sociologia da Escola Superior de Agricultura

"Luiz de Queiroz", da

Universidade de São Paulo. 
O seu custo será $C(D(p+t+l(q)))$, sendo $C$ uma função crescente. Para maximizar o lucro, assumindo-se $q$ como dado, o transportador depara-se com a seguinte situação:

$\max \{t D(p+1+l(q))-C(D(p+1+l(q)))\}$

Aplicando-se a álgebra para otimização, tem-se que: ${ }^{10}$

$t=\frac{d C}{d D}+p\left(\frac{1}{e_{D}}+\frac{1}{e_{S}}\right)$

Portanto, o transportador monopolista vai estabelecer o preço do seu frete igual ao seu custo marginal de transporte mais o produto entre o preço da commodity e a soma dos inversos da elasticidade de oferta e demanda da commodity.

O segundo caso é aquele que considera diversos pontos de demanda, em vez de apenas um. Nesse caso, uma mudança na demanda no Ponto $\mathrm{B}$ não terá nenhum impacto no preço no Ponto A, já que os compradores em B compõem uma parcela muito pequena do total de consumidores da commodity vendida pelo Ponto A. Se cada par de origem e destino é servido por um transportador diferente, não há formas de o preço do frete de um único transportador ter algum impacto sobre o preço da com-

10 A demonstração completa consta em Gameiro (2003). modity. Assim, $\frac{\partial p}{\partial t}=0$. $t=\frac{d C}{d D}+\frac{p}{e_{D}}$

Essa expressão nada mais é que a mesma (2) $\operatorname{com} e_{s}=\infty$.

O terceiro caso é aquele que tem vários pontos de oferta, cada um servido por diferentes transportadores, e apenas um ponto de demanda. O resultado é:

$t=\frac{d C}{d D}+\frac{p}{e_{s}}$

Nota-se que é uma expressão análoga a (2), mas agora $e_{D}=\infty$.

O raciocínio até então partiu do pressuposto de que há apenas um transportador monopolista realizando o frete entre um par de origem e destino. O quarto e último caso seria aquele no qual há muitos transportadores servindo os pares, caracterizando um mercado de transporte de competição perfeita. Sob essas condições, o valor do frete será simplesmente o custo marginal do serviço:

$t=\frac{d C}{d D}$

O modelo de Samuelson contribui no sentido de fundamentar a escolha dos índices mais adequados. 


\section{2_ Dados da pesquisa}

As informações de preço de frete foram levantadas pelo Projeto Sifreca e agrupadas de modo a originar preços médios mensais para cada rota específica (uma origem, um destino e uma distância), para determinado modal de transporte e produto. Para a realização desta pesquisa, foram utilizadas informações mensais do frete de soja, durante o período de 56 meses, compreendido entre janeiro de 1998 e agosto de 2002. Esse período foi particularmente caracterizado por forte instabilidade nos valores dos fretes, especialmente graças ao elevado volume da safra agrícola que vinha sendo produzido a partir de meados dos anos 90, e sem a contraparte em termos de investimentos em infraestrutura logística no País. No total, foram 10.746 informações de preço de frete para a soja a granel no período de estudo, com 1.761 combinações distintas de rotas, quais sejam: município de origem e município de destino. Os preços são dados em real por tonelada. Dividindo-se esse valor pela quilometragem da rota (que também está disponível), obteve-se o preço do frete por tonelada e por quilômetro (R $\$ / \mathrm{t} . \mathrm{km})$. Essa informação é o preço utilizado no cálculo dos índices. A distância, por sua vez, ou a quantidade de quilômetros percorridos, passa a ser a segunda informação necessária para a ponderação no cálculo dos índices: a quantidade.

Em razão de existirem diversas alternativas de procedimento (fórmulas, bases, formas de agregação, etc.) propôs-se a realização de alguns tratamentos, originados de combinações que venham a surgir do arranjo dessas alternativas. Foram testados quatro tratamentos.

O tratamento 1 partiu da hipótese de que os fretes, sendo funções das suas distâncias, ${ }^{11}$ podem ser agregados segundo essas. Independentemente das regiões de origem e destino, os fretes apresentariam o mesmo comportamento de preço desde que estivessem em uma mesma amplitude (faixa) de distância. Elegeram-se faixas de 100 quilômetros de distância. Considerando-se fretes com até 2.300 quilômetros, obtiveram-se 23 grupos. Esses são os itens incluídos na geração do índice.

No tratamento 2, diante da constatação de que as localidades de origem e destino também são determinantes do preço do frete $^{12}$ (além da distância), as informações passam a ser agregadas igualmente segundo esses fatores. Mais especificamente, utilizamse as Unidades da Federação como pontos de origem e destino. Como consequência, haverá maior número de itens (combinação de faixas de distância, Estado de ori-
11 Foram estimados modelos econométricos para testar hipóteses a respeito da influência da distância no preço e, posteriormente, sobre a influência das regiões de origem e destino nos preços. Esses modelos e seus resultados são apresentados por Gameiro (2003) e Corrêa Júnior (2001)

12 O ajuste econométrico de modelos do preço do frete em função da distância, com a inclusão de variáveis dummies para as diferentes regiões de origem e destino, evidenciou a existência de diferença significativa entre esses preços conforme algumas localidades selecionadas. A título de ilustração, os fretes com destinos nos Estados do Paraná e de São Paulo apresentam preços mais elevados para mesmas distâncias do que os destinos em Goiás e Mato Grosso. 


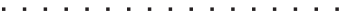

13 O termo "visibilidade" foi utilizado por Barros et al. (1997) para designar a propriedade desejada de um índice de refletir o comportamento dos preços para situações particulares (desagregadas). gem e Estado de destino) componentes do índice. O objetivo seria a obtenção de melhor visibilidade, ${ }^{13}$ dada a maior riqueza das informações desagregadas. Ocorre, porém, que esse sistema implica significativo número de observações, que podem não estar disponíveis em determinados momentos, impedindo o cálculo dos índices ou exigindo hipóteses para a viabilidade do seu cálculo matemático. Diante disso, há a necessidade de avaliar quais as fórmulas e/ou hipóteses que permitem o menor viés possível ou a melhor aproximação aos índices esperados. Neste tratamento, há 103 itens formadores da função agregação.

Nesses dois primeiros tratamentos, a informação de ponderação dos preços (a quantidade) foi considerada endógena ao sistema de levantamento das informações para construção dos índices. As quantidades foram tomadas juntamente com os preços e eram representadas pela distância (quantidade de quilômetros viajados) de cada uma das rotas, como já explicado. Essa concepção pode apresentar a vantagem de permitir o cálculo de fórmulas que exigem as ponderações nos períodos referenciais $\left(q^{t}\right.$ ou $\left.w^{t}\right)$. Entretanto, sujeita-se às limitações da amostragem (indisponibilidade de informações), que, para o caso do levantamento dos preços do frete rodoviário, é um processo bastante complexo.
Dadas as dimensões e características do setor de transporte de granéis agrícolas, a obtenção de uma informação representativa e constantemente atualizada de quantidade (seja a distância das diversas viagens, seja o peso transportado nelas) é pouco provável. E assim o é para a maioria dos índices, sejam eles de transporte, sejam eles de preços em geral. Tanto que o Índice de Laspeyres (que não exige o conhecimento da quantidade no período de cálculo, $\left.q^{t}\right)$ acaba sendo o mais utilizado na prática, como comentado.

Outra informação que seria interessante corresponderia à da quantidade de carga movimentada, em vez da quantidade de quilômetros viajados. Esse dado pode ser obtido por matrizes de origem e destino. As matrizes, porém, também não são triviais de ser geradas. Assim, provavelmente deverão fazer parte de um processo de elaboração de índices de frete (como uma exigência), a construção e revisão periódica de matrizes origem-destino para os produtos transportados.

Para o tratamento 3, o modelo econômico é o mesmo utilizado nos demais, caracterizado pelo problema de maximização do produto de transporte por parte de transportadores. No entanto, flexibiliza-se a hipótese adicional de que as quantidades são determinadas endogenamente, e as mesmas 
passam a ser fornecidas pela matriz de origem-destino, criada para esse propósito. ${ }^{14}$ Assim, apenas os preços passam a ser a solução do problema, e as quantidades se comportam como parâmetros. No tratamento 3 , há 184 itens, compostos de combinação de regiões de influência de origem e destino, com suas respectivas faixas de distância.

O tratamento 4 procura amenizar o problema da falta de informação para ponderação necessária para a formação de todos os itens, seja ela endógena, seja ela exógena. Para tanto, é utilizado um modelo econométrico contínuo, capaz de permitir a padronização de alguns determinantes do preço, como a distância, a origem e o destino, por exemplo. A flexibilidade que um processo amostral deve ter é fundamental para a elaboração de índices de preço. Entende-se por essa flexibilidade a capacidade de se estimar índices o mais representativos possível, mesmo com certas limitações, como a indisponibilidade de informações, por exemplo. A obrigatoriedade de que todas as rotas sejam levantadas em todos os períodos ( $\mathrm{CO}-$ mo no caso dos tratamentos 2 e 3 ) é uma exigência bastante forte, ainda mais quando se consideram a dimensão e as características do mercado em questão. No tratamento 4, são testadas ainda as duas fontes de ponderação: a distância (endógena) e a quan- tidade média transportada (exógena).
Sob o enfoque estatístico, uma amostragem adequada - mesmo sem a necessidade de incluir todas as rotas em todos os períodos -, deve ser capaz de possibilitar o cálculo da variação geral dos níveis de preço, sem que esses sejam significativamente influenciados por alterações em variáveis outras que, na realidade, gerariam uma alteração no produto de transporte, e não exatamente, e exclusivamente, no nível de preços, como se deseja. Observa-se que, desta forma, se está procurando considerar, de modo integrado, os enfoques estatístico e econômico para a elaboração dos índices de preço. Sob esse segundo enfoque, a premissa seria exatamente a de que apenas a variação no preço do transporte fosse mensurada, e não no seu produto. Isso pode ser obtido com a padronização de determinantes do preço, como a distância. Ter-se-ia uma aproximação para a solução de um problema de maximização de lucro para um mesmo nível de produção.

\section{Resultados}

O tratamento 1 partiu da hipótese de que os fretes, sendo função das suas distâncias, podem ser agregados exclusivamente segundo elas. A vantagem sob essa hipótese é basicamente a de que há menor exigência de informação para a elaboração

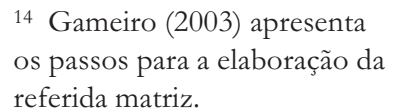


............

15 O Îndice de Palgrave apresenta o maior valor, seguido do Logaritmo Paasche. Por outro lado, os índices que apresentam os menores valores são o Harmônico Laspeyres e o Geométrico. dos índices. Os índices de frete acumulados resultantes do tratamento 1 são ilustrados na Tabela 4.

Os índices acumulados apresentam resultados significativamente distintos, variando de um mínimo de 0,9747 (Vartia I) para um máximo de 2,5313 (Palgrave). Os Índices de Walsh, Vartia II, Theil, Törnqvist e Fisher, por seu turno, apresentaram valores bastante próximos uns dos outros. Esses são os índices considerados "ideais" por Fisher (1927), por atenderem perfeitamente ou de modo bastante aproximado ao teste de reversão de fatores. Os resultados são condizentes com a clássica sistematização de Fisher para os índices em relação e seus vieses: o "garfo de cinco pontas". ${ }^{15}$
Um ponto, porém, na comparação dos índices, chama a atenção: o Índice de Laspeyres acumulado é inferior ao de Paasche. No caso de índices de custo de vida, que têm na sua concepção econômica o problema da minimização do custo do consumidor, Laspeyres apresenta forte tendência a ser maior que Paasche (ver, por exemplo, justificativa apresentada por Diewert et al., 2009). No que se refere aos índices de frete (em questão, o Índice de Paasche acumulado 1,962 foi superior ao de Laspeyres (1,579). Esse resultado está de acordo com o esperado, uma vez que a função agregação é a da maximização do produto de transporte visando ao maior lucro do transportador. Portanto, quando se pondera pelas quanti-

Tabela 4 _ Índices de fretes rodoviários para a soja de fevereiro de 1998 a março de 2002. Tratamento 1: segundo a fórmula de cálculo (bases encadeadas)

\begin{tabular}{|c|c|c|c|}
\hline Índice & Acumulado & Índice & Acumulado \\
\hline Vartia I & 0,9747 & Fisher & 1,7600 \\
\hline Harmônico Laspeyres & 1,2041 & Lowe & 1,8062 \\
\hline Geométrico & 1,3786 & Dutot & 1,8202 \\
\hline Coggeshal & 1,5369 & Jevons & 1,8222 \\
\hline Laspeyres & 1,5788 & Paasche & 1,9620 \\
\hline Walsh & 1,7488 & Carli & 2,1712 \\
\hline Vartia II & 1,7496 & Logarítimo Paasche & 2,2261 \\
\hline Theil & 1,7499 & Palgrave & 2,5313 \\
\hline Tornqvist & 1,7519 & & \\
\hline
\end{tabular}

Fonte: Gameiro (2003). 
dades no período referência (Paasche), o índice tende a apresentar um valor superior, uma vez que o aumento dos preços dos fretes mostra relação direta com o aumento na quantidade praticada. No que tange ao consumidor, ocorre exatamente o contrário: o aumento nos preços de determinado produto tende a desestimular seu consumo em detrimento de outros, reduzindo a quantidade consumida no período referência. Esse é um resultado bastante interessante desta pesquisa.

Os avanços que se esperam são no sentido de verificar se a metodologia em questão é adequada para a aplicação prática sob condições reais de pesquisa, relaxando-se algumas hipóteses e considerando a disponibilidade de informações e sua representatividade (qualidade da amostra).

É razoável se supor que um sistema de agregação por distância, origem e destino seja relevante, para ser capaz de fornecer maior visibilidade aos itens que formam o índice e, como consequência, trazer mais vantagens para os potenciais usuários da informação. Assim, o tratamento 2 procurou avaliar uma forma distinta de agregação das informações básicas. Segue-se com combinação de regiões de origem e destino (Estados brasileiros). Ademais, o modelo de Samuelson (1977) evidencia a importância geográfica da origem e do destino, ao con- siderar a elasticidade-preço dos produtos em cada uma dessas localidades. A seguir, são apresentados esses resultados.

O Índice de Carli é impossível de ser calculado quando $p^{b}$ for igual a zero, ou seja, quando não se dispõe do preço de um determinado produto ou item no período-base. O Índice de Dutot, por sua vez, não exige o sistema de informações completas, consequentemente não necessitando de hipóteses para ser calculado. Seu valor acumulado foi igual a 1,7438.

O Índice de Lowe, bem como seus derivados Laspeyres e Paasche, também não necessita de informação completa para ser calculado. No entanto, há claramente um viés quando há perda de informação. Assim sendo, já se esperava que os Índices acumulados de Laspeyres $(0,0315)$ e Paasche $(101,7902)$ apresentassem enormes vieses quando comparados aos seus índices do tratamento 1 (1,5788 e 1,9620, respectivamente) ou ao Índice de Fisher do tratamento 2 (1,7893), por exemplo. O que explica esse viés bastante significativo, e em direção contrária, é o seguinte: o Índice de Laspeyres tem viés claramente negativo em todos os períodos. Nos momentos de início de entressafra (baixa movimentação), o numerador tende a ter vários termos anulados. No início da safra, porém, a inexistência dos fretes no período anterior também 


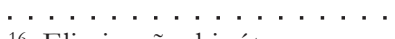

16 Eliminação: hipótese na qual se procede com a exclusão dos termos impossíveis (divisão por zero) ou que tornariam o índice igual a zero (no caso de produtórios). Suposição: hipótese caracterizada pela extrapolação de informação de preços de períodos

subsequentes, visando a evitar a eliminação dos termos, como na hipótese anterior. tende a diminuir o numerador. No Índice de Paasche, o comportamento é exatamente o mesmo, mas em sentido contrário, o que gera o viés positivo.

À primeira vista, o Índice de Fisher aparece novamente como um dos mais coerentes, mesmo para o cálculo com indisponibilidade de diversas informações. Os valores acumulados no tratamento $1(1,7600) \mathrm{e}$ no tratamento $2(1,7893)$ diferem em 2,9\%.

As análises sugerem que, apesar de haver uma compensação entre os efeitos em sentidos contrários dos Índices de Laspeyres e Paasche no longo prazo (refletida no comportamento do Índice de Fisher), há algumas distorções em meses de mudança de tendências, como início de safras e de entressafras. Em síntese, o Índice de Fisher, mesmo sendo reconhecidamente um dos superiores, deve ser visto com ressalvas no curto prazo quando em sistemas caracterizados fortemente por informações incompletas.

O Índice de Jevons é o primeiro dos índices do tipo produtório. Esses guardam a característica de exigirem os preços de ambos os períodos de comparação para o cálculo do índice. Caso o preço na base não esteja disponível, seria impossível seu cálculo. Por outro lado, se o preço no período referencial não existir (e existindo o preço na base), tornaria o índice agregado nulo. Mediante as hipóteses de eliminação e suposição, ${ }^{16} \mathrm{O}$ índice pode ser calculado, gerando valores com viés negativo quando acumulados.

O Índice de Walsh apresenta resultado bastante interessante. Sua fórmula mostra que o índice pode ser calculado com informações incompletas. Contudo, o fato de as quantidades dos períodos-base e referência participarem conjuntamente de ambos os períodos, elas exigem que essas informações estejam disponíveis para cada um dos itens; caso contrário, eliminam da fórmula as informações referentes a eles, impedindo-o de participar do cálculo. Em síntese, o índice só é calculado considerando os itens que participam em ambos os períodos de comparação. O Índice de Walsh acumulado no tratamento 2 é igual a 1,7107, valor $2,2 \%$ inferior ao do tratamento 1 , igual a 1,7488 .

O Índice de Törnqvist também é exigente em informação para sua elaboração. Por ser um índice formado por multiplicação (produtório), não admite que $p^{t}$ seja igual a zero, a não ser que $p^{b}$ também o seja. Por outro lado, $p^{b}$ também não pode ser igual a zero, o que causaria inconsistência matemática. Sob hipótese de eliminação, o índice causa um viés negativo pela perda de peso para ponderação quando o preço no período referencial $\left(p^{t}\right)$ for zero. Sob hipótese de suposição, não há perda 
de informação, e o índice acumulado foi igual a 1,8190 .

Assim como os Índices de Fisher e Walsh, considerados superiores, Törnqvist, no tratamento 2, sob a hipótese de suposição, apresentou valores bastante próximos do tratamento 1.

Os índices calculados no tratamento 3 são ilustrados resumidamente na Tabela 5. A principal diferença deste tratamento para os dois primeiros é que os preços passaram a ser ponderados pela quantidade de produto transportado (informação exógena obtida por meio de uma matriz origemdestino). Sendo essa informação não mais determinada pelo processo de amostragem, mas sim obtida de fontes secundárias.

Observa-se que um menor número de índices foi apresentado. Isso se explica pelo fato de, neste terceiro tratamento, haver vetores fixos das quantidades (pondera- ções) para todos os períodos, de modo que essas informações passam a ser equivalentes, independentemente da base, ou seja:

$q^{t}=q^{b}=q$

Com isso, do ponto de vista matemático, algumas fórmulas tornam-se equivalentes. Analisando-se as fórmulas de Lowe, Laspeyres, Paasche, Fisher e Walsh, observa-se que todas se tornam equivalentes quando a expressão (6) é verificada. Em consequência, sob hipótese de quantidades constantes, tem-se que:

$$
I_{\text {Love }}=I_{\text {Laspeyres }}=I_{\text {Paasche }}=I_{\text {Fisher }}=I_{\text {Walsh }}
$$

Assim como no tratamento 2, quando há uma informação incompleta, de $p^{b}$ ou $p^{t}$, por exemplo, e todo o resto mantido constante, há ocorrência de viés: positivo na ausência do primeiro, e negativo na ausência do segundo; uma vez que causam desfalque

Tabela 5_ Índices de fretes rodoviários para a soja de fevereiro de 1998 a março de 2002. Tratamento 3: segundo a fórmula de cálculo e hipótese

\begin{tabular}{|c|c|c|}
\hline Carli & Eliminação & 2,0982 \\
\hline Dutot & - & 1,6820 \\
\hline \multirow[t]{2}{*}{ Lowe (e derivados) } & Sem redistribuição de pesos* & 2,8722 \\
\hline & Com redistribuição de pesos* & 1,4843 \\
\hline Törnqvist & Eliminação & 1,3086 \\
\hline
\end{tabular}

(*) Estas hipóteses são explicadas nos próximos parágrafos.

Fonte: Gameiro (2003). 
na agregação, seja pela falta de $p^{b} q$ (no denominador), seja pela ausência de $p^{t} q$ (no numerador), respectivamente. Há duas soluções básicas para o impasse: a redistribuição dos pesos da base ou a extrapolação de informações de períodos anteriores aos deficitários. O primeiro procedimento é o mais utilizado, e um exemplo prático foi descrito em Gameiro (2003), quando se apresentaram os processos de mudança de base dos índices do Báltico para o mercado de afretamento de navios (Kavussanos e Nomikos, 2000).

Esse processo, consequentemente, não é capaz de captar a real influência da entrada de um determinado preço $p_{*}^{t}$ no índice. Se esse for um preço elevado, o índice estará indicando um viés baixista pela não captação desse preço elevado. Caso $p_{*}^{t}$ seja um preço baixo, o índice estará indicando um viés altista por não captar o efeito da ocorrência de um valor mais baixo na amostra. Obviamente que, no período subsequente, a ocorrência de novos aumentos ou redução em $p_{*}^{t}$, da rota inserida recentemente, será captada. Ainda assim, a influência original ficou perdida no período anterior.

No caso dos fretes agrícolas, a grande variabilidade da frequência dos serviços de transportes, como se viu, concentra-se for- temente em três ou quatro meses de colheita. Sob essas circunstâncias, muito provavelmente, a redistribuição dos pesos, quando da ausência de informação, será uma fonte clara de vieses.

No que se refere aos índices de fretes, a entrada de um grande número de novas informações na amostra, nos meses de colheita da soja, claramente ocasionaria um incremento no numerador das fórmulas derivadas de Lowe. Por outro lado, nos finais de safra, a baixa frequência dos preços $p^{t}$ tende a causar um viés negativo. Ao longo do tempo, esses deverão ir se equilibrando, ora com predominância de um, ora de outro.

Dessas análises pode-se concluir que qualquer que seja o processo eleito para lidar com o problema da falta de informações a probabilidade de haver algum viés é bastante significativa. Em outras palavras, com os métodos de cálculo de índices tradicionais, parece não haver meios eficientes de lidar com a entrada/saída periódica de informações no mercado. O próximo tratamento procurou experimentar uma possível solução para esse problema.

O tratamento 4 foi caracterizado pela utilização de funções para a obtenção das informações de preço e quantidade a ser utilizadas no cálculo dos índices. As observações amostradas no mercado são utilizadas para ajustar equações do preço em fun- 
ção da distância percorrida. ${ }^{17} \mathrm{~A}$ variável "distância do transporte" é escolhida em razão de seu papel central na determinação do preço. O objetivo principal desse procedimento foi contornar o problema da descontinuidade (falta de informação em determinado momento), tanto de preço quanto de quantidade.

Os índices calculados no tratamento 4 são apresentados, resumidamente, na Tabela 6 .

Os resultados acumulados no período apontam para índices que ficaram entre 1,7610 e 1,7838, portanto, com uma variação máxima de $1,3 \%$.

Interessante destacar que foram utilizadas informações de ponderação distintas para os índices derivados de Lowe. Apesar disso, sua variação foi bastante reduzida: de apenas $-0,9 \%$ quando se passou da ponde-

Tabela 6_ Índices de fretes rodoviários para a soja de fevereiro de 1998 a março de 2002. Tratamento 4: segundo a fórmula de cálculo e tipo de ponderação

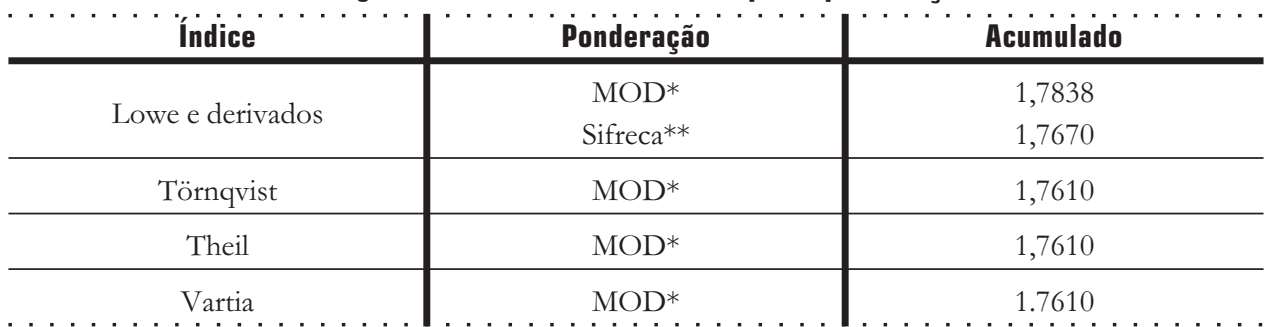

* Com informações de ponderação (quantidade transportada) originárias da matriz origem-destino.

** Com informações de ponderação (distância) originárias da base de dados do Sifreca.

Fonte: Gameiro (2003). ração obtida pela matriz origem-destino para a ponderação obtida pelas informações da base de dados do Sifreca. É um resultado bastante interessante. Ressalta-se que a matriz foi elaborada com dados de produção e consumo da soja, enquanto as informações do Sifreca refletem amostras reais de fretes praticados. Portanto, apesar de fontes distintas, chegou-se a resultados semelhantes, com indícios de que ambas são fontes bastante razoáveis de representação da distribuição das rotas.

Outro efeito que chama a atenção foi a equivalência dos resultados obtidos com as fórmulas de Törnqvist, Theil e Vartia. A explicação para isso reside no fato de que as quantidades são mantidas constantes em $b$ e $t$, de modo que matematicamente as fórmulas apresentam os mesmos resultados.

17 Foram realizados ensaios para se eleger a função a ser estimada econometricamente, como detalhado em Gameiro (2003). Os modelos considerados foram: logarítmico $(p=a+b \ln d)$, linear $(p=a+b d)$ e tipo "log-log" $(\ln p=a+b \ln d)$. Em todas essas regressões, os coeficientes apresentaram elevado nível de significância (teste " t') e coeficientes de regressão $\left(R^{2}\right)$ superiores a $60 \%$. O modelo que apresentou resultados estatísticos superiores foi o "log-log". Segundo Greene (1993), coeficientes de determinação ao redor de 50\% podem ser considerados bastante satisfatórios para dados em cross section, como no caso. 
As iniciativas de construção de índices insistem em denominar as fórmulas derivadas de Lowe, como de Laspeyres, ou mesmo "Laspeyres Modificado" - ver, por exemplo, Melo (1982) e Carmo (1987). Essa concepção não parece a mais adequada, uma vez que as ponderações não estão sendo dadas pelas informações da base, exatamente (como prevê a fórmula na sua essência), mas sim por algum sistema que permitiu a obtenção de informações de ponderação que passam a ser tomadas como fixas sem, necessariamente, terem sua origem no período-base. Pelo contrário, são obtidas, na maior parte, por amostras históricas de distribuição. Isso ocorreu no caso de alguns índices dos tratamentos $3 \mathrm{e}$ 4 do estudo apresentado. Pelo fato de ter sido o economista Lowe um dos primeiros a ter proposto a ponderação fixa, sem levar em consideração o período-base, imagina-se que esse deve ser o homenageado quando da denominação dos índices.

Diante dos resultados do tratamento 4, têm-se, na realidade, dois tipos de índice: o de Lowe (e derivados) e o equivalente a Törnqvist/Theil/Vartia. O segundo grupo é caracterizado por índices geométricos ponderados. Como Leo Törnqvist foi o precursor dessa linha de raciocínio, seu nome é sugerido para denominar o índice. Portanto, têm-se dois índices: o de Lowe e o de
Törnqvist. A comparação entre os valores acumulados entre ambos já mostrou que seu resultado foi bastante aproximado para o período completo, com um pequeno desvio de 1,3\%. Analisando-se os períodos anuais, ambos sobre a base de ponderação da matriz origem-destino, chega-se a diferenças percentuais de $0,5 \%$ (em 1998), - $0,93 \%$ (em 1999), $0,7 \%$ (em 2000) e 1,4\% (em 2001). Portanto, diferenças inferiores a $1,5 \%$, para mais ou para menos.

Em síntese, com as informações obtidas, pode-se dizer que a variação acumulada do preço do frete para a soja a granel no Brasil, entre fevereiro de 1998 e março de 2002 , foi de $76 \%$. Esse resultado está de acordo com a experiência empírica obtida com o acompanhamento do mercado.

No tratamento 1, os índices superiores foram: Fisher, Walsh, Theil, Törnqvist e Vartia. A diferença entre eles foi bastante pequena, de modo que sua escolha pode ser arbitrária. Elege-se, para comparação com os índices do tratamento 4, o Índice de Fisher, por ser o mais consagrado na literatura.

No tratamento 2, surge o problema da falta de informação completa, o que incorre em fortes vieses para alguns índices. Os índices ideais continuam sendo os superiores. A exceção é o de Fisher, que, por ser derivado de Laspeyres e Paasche (que são altamente enviesados pela falta de infor- 
mação), acaba sendo prejudicado. Walsh, Törnqvist e Theil continuam como os mais indicados. No entanto, os dois últimos só podem ser calculados mediante a adoção de hipóteses para a solução da inconsistência matemática originada pela falta de dados. Essas hipóteses fatalmente levam a vieses, por menores que sejam. O Índice de Walsh desponta como superior, e, de fato, as análises de correlação com seu correspondente do tratamento 1 o reforçam como o mais indicado. Diante dessas evidências, Walsh é eleito o índice para servir de comparação com o tratamento 4.

No terceiro tratamento, continua presente o problema da falta de informação. Mas essa carência é amenizada pela consideração de um sistema fixo de ponderação, o que resolve a falta de informação de quantidade, mas mantém o problema da inexistência periódica dos preços. Nesse tratamento, assim como no quarto, as fórmulas acabam sendo reduzidas às de Lowe e seus derivados, e às dos índices geométricos ponderados (Törnqvist e Vartia). Como já mencionado, os índices geométricos exigem a presença de informações completas $\left(p^{b}\right.$ e $\left.p^{t}\right)$ e preços, de modo que só são passíveis de cálculo mediante a imposição de hipóteses. Resta o Índice de Lowe. Esse pode ser calculado sem a redistribuição dos pesos, o que gera vieses enormes, pelos motivos apre- sentados anteriormente; ou com a redistribuição dos pesos, que é o procedimento clássico adotado pelos elaboradores de índice para a alteração dos índices pela entrada/saída/substituição de itens. Esse é considerado o índice superior do tratamento 3, ainda que claramente traga consigo vieses, conforme já analisado. Assim, o Índice de Lowe (com redistribuição de pesos) é o escolhido para comparação com os índices do tratamento 4.

$\mathrm{Na}$ Tabela 7, apresentam-se as principais observações qualitativas sobre os tratamentos e sua aplicação empírica. Os comentários ao seu respeito são apresentados no capítulo conclusivo.

\section{5_Conclusões}

Uma importante conclusão é a de que, além do fundamento teórico, um índice sempre deve ser testado empiricamente. Isso, pelo fato de que sempre será uma simplificação ou uma aproximação da realidade. O objetivo deveria ser a obtenção do melhor índice com o processo amostral possível. A carência de informação é uma realidade presente na maioria dos projetos de elaboração de índices e deve ser tratada de modo a não prejudicar significativamente o resultado final. 
Tabela 7 Resumo das principais observações resultantes dos tratamentos

\begin{tabular}{|c|c|c|c|c|}
\hline \multirow{2}{*}{ Observações } & \\
\hline & 1 & 2 & 3 & 4 \\
\hline Ponderação & Distância & Distância & Produção escoada & $\begin{array}{l}\text { Distância e } \\
\text { Produção escoada }\end{array}$ \\
\hline Índice referência & Fisher & Walsh & $\begin{array}{l}\text { Lowe (com } \\
\text { redistribuição de pesos) }\end{array}$ & Törnqvist \\
\hline Índice acumulado & 1,7600 & 1,7107 & 1,4843 & 1,7610 \\
\hline $\begin{array}{l}\text { Efeito negativo da escassez } \\
\text { de informação }\end{array}$ & Média & Alta & Alta & Baixa \\
\hline $\begin{array}{l}\text { Dificuldade de } \\
\text { operacionalizar o processo } \\
\text { de amostragem }\end{array}$ & Média & Alta & Muito alta & Média \\
\hline $\begin{array}{l}\text { Visibilidade obtida por } \\
\text { meio dos subíndices }\end{array}$ & $\begin{array}{l}\text { Baixa. Subíndices } \\
\text { relacionados apenas a } \\
\text { faixas de distância. }\end{array}$ & $\begin{array}{l}\text { Média. Subíndices } \\
\text { relacionados a faixas } \\
\text { de distância e grupos } \\
\text { de rotas tendo Estados } \\
\text { como origem e destino. }\end{array}$ & $\begin{array}{l}\text { Alta. Subíndices } \\
\text { relacionados a faixas } \\
\text { de distância e grupos } \\
\text { de rotas tendo regiões } \\
\text { bem definidas de origem } \\
\text { e destino. }\end{array}$ & $\begin{array}{l}\text { A precisão dos modelos } \\
\text { de previsão de subíndices } \\
\text { específicos está } \\
\text { condicionada ao } \\
\text { comportamento desses } \\
\text { fretes, devendo } \\
\text { ser avaliada } \\
\text { econometricamente } \\
\text { dentro dos níveis de } \\
\text { significância desejados. }\end{array}$ \\
\hline $\begin{array}{l}\text { Qualidade esperada } \\
\text { para o índice geral }\end{array}$ & Adequada & $\begin{array}{l}\text { Baixa. Diante da falta de } \\
\text { de extrapolação (estabele } \\
\text { períodos precedentes ou } \\
\text { redistribuição das ponde }\end{array}$ & $\begin{array}{l}\text { formação, há a necessidade } \\
\text { mento de hipóteses) de } \\
\text { steriores, ou a } \\
\text { ões, gerando vieses. . . . . . }\end{array}$ & Adequada \\
\hline
\end{tabular}

Fonte: Gameiro (2003).

A falta ou indisponibilidade da informação não é devida, necessariamente, ao problema amostral. Em diversas circunstâncias, determinada informação simplesmente pode não ter ocorrido. Esse é um ponto que há muito inquieta os estudiosos dos números-índice: a entrada e/ou saída de informações na amostra pode gerar variação no índice não decorrente da variação no nível de preços, mas sim da 
mera combinação distinta das informações disponíveis. Essa indisponibilidade de informação é representada por uma descontinuidade - ao longo do tempo - no nível de preço dos fretes para determinadas situações (itens na agregação). Tal descontinuidade pode decorrer da sazonalidade característica da logística de transporte dos produtos de origem agrícola.

A forma encontrada para o tratamento dessa descontinuidade foi a utilização de funções que tivessem o preço que se deseja medir determinado por características controláveis (e observáveis), tais como o tipo de carga, a sua quantidade, o acondicionamento, a localidade de origem, de destino, a distância, etc. Foram, assim, realizados quatro tratamentos objetivando entender o comportamento dos dados e o resultado da aplicação da metodologia de construção dos índices sobre esses. Os tratamentos 1 e 4 mostraram-se mais adequados para a obtenção de um índice para o nível geral dos preços. O primeiro, entretanto, apresenta baixa capacidade de fornecer informações desagregadas (subíndices), uma vez que exibe apenas agrupamento por faixas de distância.

O quarto tratamento, por utilizar previsões para os preços a partir das distâncias, deve ser considerado com ressalvas no fornecimento de subíndices específicos. É importante que sejam estipulados intervalos de confiança para esse processo. A principal vantagem que se espera desse tratamento é o conhecimento do nível geral dos preços sem perda de informação. Esse tratamento, sob o ponto de vista das aproximações, parece bastante razoável: atende à maior parte dos testes axiomáticos, utiliza fundamentos econométricos (portanto, estatísticos) para a obtenção dos índices e - talvez o mais importante - utiliza uma função econômica que, estimada, fornece uma relação entre preço (p) e quantidade (q), atendendo ao consagrado enfoque econômico. 


\section{Referências bibliográficas}

BARROS, G. S. C.; MARQUES, P. V.; BACCHI, M. R. P.; CAFFAGNI, L. C. Elaboração de indicadores de preços da soja: um estudo preliminar. Piracicaba: ESALQ, Centro de Estudos Avançados em Economia Aplicada, 1997. 89p.

CAIXETA FILHO, J. V.;

GAMEIRO, A. H. (Org.). Transporte e logística em sistemas agroindustriais. São Paulo: Editora Atlas, 2001.

CARLI, G. R. Del valore e della proporzione de'metalli monetari con i generi in Italia prima delle scoperte dell'Indie colonfronto del valore e della proporzione de'tempi nostri. Opere scelte di Carli, v. 1, p. 299-366, 1764.

\section{CARMO, H. C. E. Um enfoque} integrado para números-índice econômicos: uma aplicação ao cálculo de preços ao consumidor no município de São Paulo no período 1939-1986. 1987. 260p. Tese (Doutorado em Teoria Econômica) - Faculdade de Economia, Administração e Contabilidade, Universidade de São Paulo, São Paulo, 1987.

CORRÊA-JÚNIOR, G. Principais determinantes do preço do frete rodoviário para transporte de soja em grãos em diferentes regiões brasileiras: uma análise econométrica. 2001. 102p. Dissertação (Mestrado em
Economia Aplicada) - Escola Superior de Agricultura "Luiz de Queiroz”, Universidade de São Paulo, Piracicaba, 2001.

DIEWERT, W. E. Exact and Superlative Index Numbers, Journal of Econometrics, v. 4, p. $114-145,1976$.

DIEWERT, W. E. Superlative Index Numbers and Consistency in Aggregation, Econometrica, v. 46, p. 883-900, 1978 .

DIEWERT, W. E. The Economic Theory of Index Numbers: A Survey, p. 163-208 in Essays in the Theory and Measurement of Consumer Behaviour in Honour of Sir Richard Stone, edited by

A. Deaton, Cambridge UK: Cambridge University Press, 1981

DIEWERT, W. E. Index numbers. In: EATWELL, M. M.; NEWMAN, J. (Ed.). The new Palgrave: a dictionary of Economics. London: Macmillan, p. $767-780,1987$.

DIEWERT, W. E. Test Approaches to International Comparisons, p. 67-86 in Measurement in Economics: Theory and Applications of Eco-nomic Indices, W. Eichhorn (ed.), Heidelberg: Physica-Verlag. 1988.
DIEWERT, W. E. The consumer price index and index numbers theory: a survey. Vancouver: The University of British Columbia, 2001. 103p. (Discussion paper 01-02)

DIEWERT, W. E. A New Axiomatic Approach to Index Number Theory, Discussion Paper 04-05,

Department of Economics, University of British Columbia, Vancouver, Canada, V6T 1Z1, 2004

DIEWERT, W. E.; HUWILER, M.; KOHLI, U. Retrospective Price Indices and Substitution Bias. Discussion Paper 09-01. Department of Economics. Vancouver: University of British Columbia, $11 \mathrm{p}, 2009$.

DIEWERT, W. E.; HILL, R. J. Comment on Different Approaches to Index Number Theory. Discussion Paper 09-05. Department of Economics. Vancouver: University of British Columbia, 18p (Revised in January 20, 2009).

DIEWERT, W. E. Cost of Living Indexes and Exact Index Numbers.

Discussion Paper 09-06.

Department of Economics. Vancouver: University of British Columbia, 35p (Revised in August 6, 2009).
DIVISIA, F. L'Indice Monetaire et la Théorie de La Monnaie. Revue d'Economie Politique. Tome XXXIX, juil./aôut p. 842-861 e sept./oct., p. $980-1008,1925$.

DUTOT, C. F. Réflexions politiques sur les finances et el commerce. La Haye: Antoine van Dole, 1738.

EICHHORN, W.; HENN, R.; OPITZ, O.; SHEPAHRD (Ed.). Theory and Applications of Economic Indices. Würzburg: Physica-Verlag, 1978. p. 271-295.

EICHHORN, W.; VOELLER, J.

Theory of the price index: Fisher's test approach and generalizations. Lecture Notes in Economics and Mathematical Systems, v. 140, Berlin: Springer-Verlag, 1976

FISHER, I. The making of index numbers: a study of their varieties, tests and reliability. Boston: Houghton Mifflin Co., 1927. Reprinted. New York: Augustos M. Kelley, 1967.

FRISCH, R. O problema dos números índices. Revista Brasileira de Estatística, v. 11, n. 42, p. 187-214, abr./jun., 1950. 
FUNKE, H.; HACKER, A. G.; VOELLER, J. Fisher's Circular Test Reconsidered. Schweizerische Zeitschrift für Volkswirtshaft und Statistik, v. 115, p. 677-687, 1979 .

GAMEIRO, A. H. Índices de preço para o transporte de cargas: o caso da soja a granel. 2003.284p. Tese (Doutorado em ??) - Escola Superior de Agricultura "Luiz de Queiroz", Universidade de São Paulo, São Paulo, 2003.

GREENE, W. H. Econometric analysis. 2. ed. Englewood Cliffs: Prentice Hall, 1993. 791p

JEVONS, W. S. Theory of Political Economy. 2. ed. London: Macmillan and Co., 1879. 339p.

\section{KAVUSSANOS, M. G.;}

NOMIKOS, N. Futures hedging when the structure of the underlying asset changes: the case of the BIFFEX contract. The Journal of Futures Markets, v. 20, n. 8, p. $775-801,2000$

KENDALL, M. G. The early history of index numbers. In: Studies in the History of Probability and Statistics. International Statistical Review. v. 37, 1969.

KONÜS, A. A. The problem of the true cost of living. Econometrica, v. 7 , p. 10-29, 1939 .

\section{LASPEYRES, E. Die}

Berechnung einer mittleren

Warenpreissteigerung. Jabrbücker für Nationalökonomie und Statistik. v. 16, p. $296-314,1871$
MELO, F. A. M. Análise dos indices de precos e estimativas de seus vieses. 1982. 132p. Dissertação (Mestrado em 1982) - Fundação Getúlio Vargas, Rio de Janeiro, 1982.

PAASCHE, H. Über die Preisentwicklung der letzten Jahre nach den Hamburger

Börsennotirungen. Jabrbücker für

Nationalökonomie und Statistik. v. 23, p. $168-178,1874$

\section{PIERSON, N. G. Further}

Considerations on Index-Numbers. Economic Journal, v. 6,

p. 127-131, 1896 .

PERSKY, J. Price indexes and general exchange values. Journal of Economic Perspectives, v. 12, n. 1, p. 197-205, Winter 1998.

SAMUELSON, R. Modeling the freight rate structure. Cambridge: MIT,

Center for Transportation Studies, Feb. 1977. 1v. (Report, 77-7)

THEIL, H. Best linear index number of prices and quantities. Econometrica, v. 28, n. 2, p. 464-480, abr. 1960.

THEIL, H. A new index number formula. Review of Economics and Statistics, v. 55, n. 4, p. 499-503, 1974.

VAN VEELEN, M.; VAN DER WEIDE, R. A Note on Different Approaches to Index Number Theory, American Economic Review, v. 98 , n. 4, p. 1722-1730, 2008

VARTIA, Y. Relative change and index number. Helsinki: The Research

Institute of the Finnish

Economy, 1976.
WALSH, C. M. The measurement of general exchange value. New York: The Macmillan Company, 1901.138p.

WALSH, C. M. The best form of index number: discussion. Quarterly Publication of the American Statistical Association, v. 17, p. 537-544, 1921.

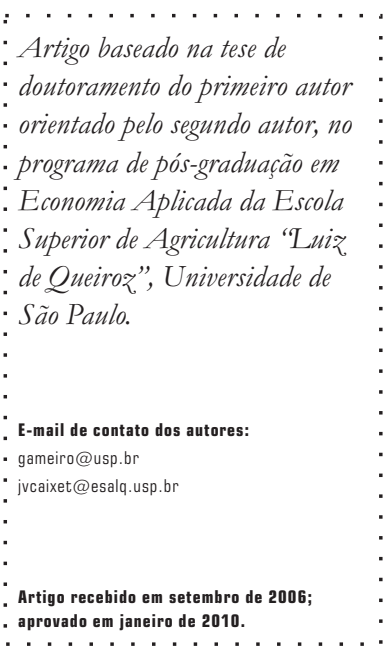


Anexos - Índices de fretes calculados

Tahela 1A_ Índices de fretes rodoviários mensais para a soja a granel de fevereiro de 1998 a março de 2002. Tratamento 1: bases encadeadas

\begin{tabular}{|c|c|c|c|c|c|c|c|c|}
\hline $\mathrm{mar} / 98$ & 1,1634 & 1,1671 & 1,1367 & 1,1671 & 1,1146 & 1,1514 & 1,1329 & 1,1533 \\
\hline $\mathrm{abr} / 98$ & 1,0425 & 1,0667 & 1,0274 & 1,0256 & 1,0174 & 1,0202 & 1,0188 & 1,0372 \\
\hline $\mathrm{mai} / 98$ & 0,9067 & 0,8812 & 0,9149 & 0,9246 & 0,9201 & 0,9209 & 0,9205 & 0,9029 \\
\hline jun/98 & 1,0432 & 1,0480 & 1,0346 & 1,0322 & 1,0328 & 1,0274 & 1,0301 & 1,0408 \\
\hline jul/98 & 0,9953 & 0,9934 & 0,9919 & 0,9928 & 0,9944 & 0,9904 & 0,9924 & 0,9941 \\
\hline ago/98 & 1,0267 & 1,0226 & 1,0353 & 1,0295 & 1,0350 & 1,0274 & 1,0312 & 1,0256 \\
\hline set/98 & 0,9815 & 0,9851 & 0,9862 & 0,9715 & 0,9736 & 0,9695 & 0,9715 & 0,9803 \\
\hline out $/ 98$ & 0,9412 & 0,9449 & 0,9448 & 0,9394 & 0,9339 & $\begin{array}{l}0,9371 \\
\end{array}$ & 0,9355 & 0,9399 \\
\hline nov $/ 98$ & 0,9671 & 0,9515 & 0,9700 & 0,9679 & 0,9737 & 0,9631 & 0,9684 & 0,9642 \\
\hline jan/99 & 1,0079 & 1,0042 & 1,0085 & 1,0178 & 1,0079 & 1,0160 & 1,0119 & 1,0070 \\
\hline $\mathrm{fev} / 99$ & 1,1489 & 1,1330 & 1,1261 & 1,1778 & 1,1463 & 1,1648 & 1,1555 & 1,1427 \\
\hline $\mathrm{mar} / 99$ & 1,1138 & 1,1255 & 1,1032 & 1,0929 & 1,0886 & 1,0896 & 1,0891 & 1,1099 \\
\hline abr/99 & 1,0311 & 1,0283 & 1,0380 & 1,0504 & 1,0191 & 1,0441 & 1,0315 & 1,0277 \\
\hline mai/99 & 0,9344 & 0,9307 & 0,9341 & 0,9454 & 0,9406 & 0,9432 & 0,9419 & 0,9324 \\
\hline jun/99 & 0,9717 & 0,9639 & 0,9644 & 0,9679 & 0,9612 & 0,9646 & 0,9629 & 0,9696 \\
\hline jul/99 & 0,9994 & 0,9915 & 0,9984 & 1,0037 & 0,9964 & 0,9994 & 0,9979 & 0,9976 \\
\hline ago/99 & 1,0630 & 1,0652 & 1,0555 & 1,0609 & 1,0488 & 1,0589 & 1,0538 & 1,0619 \\
\hline set/99 & 1,0214 & 1,0236 & 1,0167 & 1,0189 & 1,0173 & 1,0179 & 1,0176 & 1,0209 \\
\hline $\mathrm{dez} / 99$ & 0,9649 & 0,9669 & 0,9681 & 0,9701 & 0,9661 & 0,9689 & 0,9675 & 0,9641 \\
\hline jan $/ 00$ & 1,0255 & 1,0451 & 1,0151 & 0,9979 & 1,0345 & 0,9944 & 1,0143 & 1,0209 \\
\hline $\mathrm{fev} / 00$ & 0,9970 & 0,9811 & 0,9987 & 1,0126 & 1,0029 & 1,0099 & 1,0064 & 0,9950 \\
\hline $\mathrm{mar} / 00$ & 1,0521 & 1,0432 & 1,0595 & 1,0951 & 1,0440 & 1,0861 & 1,0649 & 1,0457 \\
\hline $\mathrm{abr} / 00$ & 1,1144 & 1,1121 & 1,1049 & 1,1126 & 1,0963 & 1,1064 & 1,1014 & 1,1096 \\
\hline $\mathrm{mai} / 00$ & 0,9994 & 0,9827 & 0,9788 & 0,9764 & 0,9679 & 0,9711 & 0,9695 & 0,9912 \\
\hline jun $/ 00$ & 0,9931 & 0,9905 & 0,9842 & 0,9792 & 0,9853 & 0,9731 & 0,9792 & 0,9895 \\
\hline $\mathrm{jul} / 00$ & 0,9911 & 0,9907 & 0,9880 & 0,9900 & 0,9972 & 0,9858 & 0,9915 & 0,9887 \\
\hline ago/00 & 0,9572 & 0,9574 & 0,9500 & 0,9662 & 0,9604 & 0,9580 & 0,9592 & 0,9506 \\
\hline set $/ 00$ & 0,9978 & 0,9853 & 0,9972 & 1,0125 & 1,0056 & 1,0079 & 1,0067 & 0,9953 \\
\hline out $/ 00$ & 0,9852 & 0,9833 & 0,9876 & 0,9943 & 0,9862 & 0,9885 & 0,9873 & 0,9800 \\
\hline nov $/ 00$ & 0,9639 & 0,9712 & 0,9590 & 0,9656 & 0,9314 & 0,9607 & 0,9459 & 0,9604 \\
\hline $\mathrm{dez} / 00$ & 0,9913 & 0,9864 & 0,9950 & 1,0085 & 1,0075 & 1,0070 & 1,0073 & 0,9899 \\
\hline jan/01 & 1,0745 & 1,0644 & 1,0667 & 1,0706 & 1,0529 & 1,0607 & 1,0568 & 1,0700 \\
\hline $\mathrm{fev} / 01$ & 1,0262 & 1,0206 & 1,0254 & 1,0316 & 1,0276 & 1,0291 & 1,0283 & 1,0245 \\
\hline $\mathrm{mar} / 01$ & 1,1751 & 1,1920 & 1,1985 & 1,2516 & 1,1842 & 1,2347 & 1,2092 & 1,1645 \\
\hline $\mathrm{abr} / 01$ & 0,9755 & 0,9803 & 0,9691 & 0,9812 & 0,9720 & 0,9793 & 0,9756 & 0,9735 \\
\hline $\mathrm{mai} / 01$ & 0,9466 & 0,9314 & 0,9307 & 0,9185 & 0,9118 & 0,9139 & 0,9128 & 0,9447 \\
\hline jun/01 & 1,0381 & 1,0233 & 1,0204 & 1,0577 & 1,0158 & 1,0440 & 1,0298 & 1,0307 \\
\hline out $/ 01$ & 0,9357 & 0,9361 & 0,9324 & 0,9247 & 0,9259 & 0,9227 & 0,9243 & 0,9347 \\
\hline nov $/ 01$ & 1,0367 & 1,0466 & 1,0186 & 1,0166 & 1,0174 & 1,0127 & 1,0150 & 1,0318 \\
\hline $\mathrm{dez} / 01$ & 1,0739 & 1,0438 & 1,0752 & 1,0777 & 1,0312 & 1,0534 & 1,0422 & 1,0535 \\
\hline jan $/ 02$ & 1,0639 & 1,0441 & 1,0551 & 1,0788 & 1,0671 & 1,0673 & 1,0672 & 1,0576 \\
\hline $\mathrm{fev} / 02$ & 1,0240 & 1,0139 & 1,0127 & 1,0433 & 1,0394 & 1,0308 & 1,0351 & 1,0172 \\
\hline $\mathrm{mar} / 02$ & 1,0577 & 1,0534 & 1,0609 & 1,0850 & 1,0586 & 1,0788 & 1,0686 & 1,0544 \\
\hline Acumulado & 2,1712 . & 1,8202 & 1,8062 & 2,5313 . & 1,5788. & . 1,9620 . & 1,7600 & 1,8222 \\
\hline
\end{tabular}

Fonte: Gameiro (2003). 
Tabela 2A_ Índices de fretes rodoviários mensais para a soja a granel de fevereiro de 1998 a março de 2002.

Tratamento 1: bases encadeadas

\begin{tabular}{|c|c|c|c|c|c|c|c|c|c|}
\hline Mês & Geométrico & Walsh & Coggeshal & $\begin{array}{l}\text { Logarítimo } \\
\text { Paasche }\end{array}$ & $\begin{array}{l}\text { Harmônico } \\
\text { Laspeyres }\end{array}$ & Tornquist & Theil & Vartia I & Vartia I \\
\hline mar $/ 98$ & 1,1084 & 1,1296 & 1,1437 & 1,1591 & 1,1025 & 1,1335 & 1,1307 & 1,0072 & 1,1309 \\
\hline $\mathrm{abr} / 98$ & 1,0150 & 1,0166 & 1,0326 & 1,0228 & 1,0127 & 1,0189 & 1,0173 & 0,9992 & 1,0173 \\
\hline $\mathrm{mai} / 98$ & 0,9177 & 0,9212 & 0,8986 & 0,9228 & 0,9153 & 0,9203 & 0,9209 & 0,9976 & 0,9209 \\
\hline jul/98 & 0,9931 & 0,9923 & 0,9929 & 0,9916 & 0,9918 & 0,9924 & 0,9923 & 0,9993 & 0,9923 \\
\hline ago/98 & 1,0339 & 1,0310 & 1,0246 & 1,0285 & 1,0328 & 1,0312 & 1,0311 & 1,0021 & 1,0311 \\
\hline set $/ 98$ & 0,9723 & 0,9713 & 0,9792 & 0,9705 & 0,9710 & 0,9714 & 0,9713 & 0,9975 & 0,9713 \\
\hline out $/ 98$ & 0,9324 & 0,9347 & 0,9385 & 0,9383 & 0,9310 & 0,9353 & 0,9349 & 0,9963 & 0,9349 \\
\hline $\mathrm{dez} / 98$ & 0,9639 & 0,9631 & 0,9668 & 0,9622 & 0,9625 & 0,9630 & 0,9631 & 0,9998 & 0,9631 \\
\hline jan/99 & 1,0073 & 1,0092 & 1,0060 & 1,0169 & 1,0068 & 1,0121 & 1,0100 & 1,0099 & 1,0102 \\
\hline $\mathrm{fev} / 99$ & 1,1393 & 1,1527 & 1,1364 & 1,1714 & 1,1322 & 1,1553 & 1,1536 & 1,0072 & 1,1536 \\
\hline $\mathrm{mar} / 99$ & 1,0870 & 1,0892 & 1,1065 & 1,0912 & 1,0854 & 1,0891 & 1,0892 & 1,0042 & 1,0892 \\
\hline abr/99 & 1,0165 & 1,0317 & 1,0245 & 1,0472 & 1,0141 & 1,0317 & 1,0317 & 0,9990 & 1,0317 \\
\hline mai/99 & 0,9390 & 0,9421 & 0,9302 & 0,9443 & 0,9374 & 0,9417 & 0,9420 & 0,9970 & 0,9420 \\
\hline jun $/ 99$ & 0,9602 & 0,9621 & 0,9677 & 0,9662 & 0,9593 & 0,9632 & 0,9624 & 1,0010 & 0,9624 \\
\hline jul/99 & 0,9945 & 0,9976 & 0,9958 & 1,0016 & 0,9926 & 0,9980 & 0,9978 & 0,9982 & 0,9978 \\
\hline ago/99 & 1,0474 & 1,0541 & 1,0607 & 1,0599 & 1,0459 & 1,0536 & 1,0539 & 1,0098 & 1,0539 \\
\hline nov/99 & 0,9818 & 0,9826 & 0,9748 & 0,9833 & 0,9812 & 0,9825 & 0,9826 & 0,9990 & 0,9826 \\
\hline $\mathrm{dez} / 99$ & 0,9654 & 0,9675 & 0,9633 & 0,9695 & 0,9646 & 0,9674 & 0,9675 & 0,9981 & 0,9675 \\
\hline $\mathrm{jan} / 00$ & 1,0293 & 1,0091 & 1,0169 & 0,9960 & 1,0248 & 1,0125 & 1,0102 & 1,0053 & 1,0102 \\
\hline $\mathrm{fev} / 00$ & 1,0019 & 1,0061 & 0,9930 & 1,0112 & 1,0008 & 1,0065 & 1,0062 & 1,0015 & 1,0062 \\
\hline $\mathrm{mar} / 00$ & 1,0367 & 1,0696 & 1,0389 & 1,0907 & 1,0288 & 1,0634 & 1,0679 & 1,0074 & 1,0675 \\
\hline $\mathrm{abr} / 00$ & 1,0933 & 1,1015 & 1,1047 & 1,1095 & 1,0905 & 1,1014 & 1,1015 & 0,9606 & 1,1015 \\
\hline $\mathrm{mai} / 00$ & 0,9657 & 0,9697 & 0,9847 & 0,9735 & 0,9638 & 0,9696 & 0,9696 & 0,9659 & 0,9696 \\
\hline jun $/ 00$ & 0,9813 & 0,9783 & 0,9859 & 0,9762 & 0,9773 & 0,9787 & 0,9784 & 0,9985 & 0,9785 \\
\hline $\mathrm{jul} / 00$ & 0,9957 & 0,9926 & 0,9861 & 0,9880 & 0,9942 & 0,9918 & 0,9924 & 0,9978 & 0,9924 \\
\hline ago/ 00 & 0,9537 & 0,9587 & 0,9440 & 0,9621 & 0,9469 & 0,9579 & 0,9584 & 0,9977 & 0,9584 \\
\hline set $/ 00$ & 1,0043 & 1,0075 & 0,9929 & 1,0102 & 1,0031 & 1,0072 & 1,0074 & 1,0013 & 1,0074 \\
\hline out $/ 00$ & 0,9824 & 0,9870 & 0,9745 & 0,9914 & 0,9784 & 0,9869 & 0,9870 & 0,9989 & 0,9870 \\
\hline nov $/ 00$ & 0,9275 & 0,9499 & 0,9568 & 0,9632 & 0,9237 & 0,9452 & 0,9485 & 0,9771 & 0,9483 \\
\hline $\mathrm{dez} / 00$ & 1,0065 & 1,0075 & 0,9884 & 1,0078 & 1,0055 & 1,0072 & 1,0074 & 0,9991 & 1,0074 \\
\hline jan/01 & 1,0495 & 1,0560 & 1,0655 & 1,0656 & 1,0461 & 1,0576 & 1,0565 & 1,0040 & 1,0565 \\
\hline $\mathrm{fev} / 01$ & 1,0263 & 1,0283 & 1,0229 & 1,0303 & 1,0250 & 1,0283 & 1,0283 & 0,9981 & 1,0283 \\
\hline $\mathrm{mar} / 01$ & 1,1718 & 1,2144 & 1,1535 & 1,2434 & 1,1590 & 1,2071 & 1,2122 & 1,0154 & 1,2119 \\
\hline $\mathrm{abr} / 01$ & 0,9706 & 0,9759 & 0,9715 & 0,9802 & 0,9691 & 0,9754 & 0,9758 & 0,9974 & 0,9758 \\
\hline $\mathrm{mai} / 01$ & 0,9096 & 0,9125 & 0,9428 & 0,9162 & 0,9074 & 0,9129 & 0,9127 & 0,9945 & 0,9127 \\
\hline set/01 & 0,9598 & 0,9640 & 0,9791 & 0,9678 & 0,9577 & 0,9638 & 0,9639 & 0,9970 & 0,9639 \\
\hline out/01 & 0,9250 & 0,9244 & 0,9336 & 0,9237 & 0,9240 & 0,9243 & 0,9244 & 0,9968 & 0,9244 \\
\hline nov/01 & 1,0146 & 1,0142 & 1,0275 & 1,0146 & 1,0120 & 1,0146 & 1,0143 & 1,0005 & 1,0143 \\
\hline $\mathrm{dez} / 01$ & 1,0241 & 1,0419 & 1,0374 & 1,0640 & 1,0184 & 1,0438 & 1,0423 & 1,0097 & 1,0424 \\
\hline $\mathrm{jan} / 02$ & 1,0618 & 1,0673 & 1,0511 & 1,0732 & 1,0563 & 1,0675 & 1,0674 & 1,0045 & 1,0674 \\
\hline $\mathrm{fev} / 02$ & 1,0322 & 1,0347 & 1,0096 & 1,0374 & 1,0242 & 1,0348 & 1,0348 & 1,0018 & 1,0348 \\
\hline $\mathrm{mar} / 02$ & 1,0558 & 1,0686 & 1,0511 & 1,0819 & 1,0530 & 1,0688 & 1,0687 & 1,0118 & 1,0687 \\
\hline Acumulado & 1,3786 & 1,7488 & 1,5369 & .2,2261. & 1,2041. & 1,7519 . & 1,7499 & 0,9747 & 1,7496 \\
\hline
\end{tabular}

Fonte: Gameiro (2003). 
Tabela 3A_ Índices de fretes rodoviários mensais para a soja a granel de fevereiro de 1998 a março de 2002. Tratamento 2: bases encadeadas

\begin{tabular}{|c|c|c|c|c|c|c|c|c|}
\hline Mês & Eliminação & Suposição & Dutot & Lowe & & Laspeyres & Paasche \\
\hline $\mathrm{mar} / 98$ & 1,1351 & 1,0969 & 1,1193 & 1,2228 & 0,9961 & 1,1402 & 1,1102 & 1,3441 \\
\hline $\mathrm{abr} / 98$ & 1,0661 & 1,0397 & 1,0518 & 0,9680 & 0,9606 & 1,0387 & 0,8801 & 1,1224 \\
\hline $\mathrm{mai} / 98$ & 0,9160 & 0,9290 & 0,9308 & 1,0805 & 0,7633 & 0,9394 & 0,8843 & 1,1284 \\
\hline jun $/ 98$ & 1,0447 & 1,0354 & 1,0272 & 1,0457 & 1,0334 & 1,0520 & 1,0373 & 1,0698 \\
\hline jul/98 & 1,0012 & 0,9937 & 0,9834 & 1,0170 & 0,9758 & 1,0019 & 0,9849 & 1,0281 \\
\hline ago/98 & 0,9967 & 0,9987 & 1,0174 & 0,9573 & 0,9981 & 1,0076 & 0,9371 & 1,0123 \\
\hline set/98 & 0,9999 & 0,9980 & 1,0182 & 0,9606 & 0,9662 & 0,9797 & 0,9346 & 0,9902 \\
\hline out/98 & 0,9335 & 0,9486 & 0,9513 & 0,9175 & 0,9166 & 0,9252 & 0,8810 & 0,9315 \\
\hline nov $/ 98$ & 0,9534 & 0,9714 & 0,9713 & 0,9032 & 0,9429 & 0,9429 & 0,8626 & 0,9390 \\
\hline $\operatorname{dez} / 98$ & 0,9680 & 0,9828 & 0,9674 & 0,9648 & 0,9498 & 0,9579 & 0,9485 & 0,9583 \\
\hline jan/99 & 1,0087 & 1,0051 & 1,0034 & 1,0055 & 1,0115 & 1,0115 & 1,0022 & 1,0090 \\
\hline fev/99 & 1,1148 & 1,1004 & 1,0546 & 1,3115 & 0,9290 & 1,1630 & 1,1397 & 1,4576 \\
\hline $\mathrm{mar} / 99$ & 1,1065 & 1,0913 & 1,1011 & 1,1282 & 1,0931 & 1,1102 & 1,0776 & 1,1159 \\
\hline $\mathrm{abr} / 99$ & 1,0858 & 1,0630 & 1,1156 & 1,0196 & 1,0245 & 1,1025 & 0,9463 & 1,1525 \\
\hline $\mathrm{mai} / 99$ & 0,9342 & 0,9523 & 0,9290 & 0,9235 & 0,9027 & 0,9297 & 0,9060 & 0,9473 \\
\hline jun/99 & 0,9779 & 0,9833 & 0,9659 & 0,9522 & 0,9575 & 0,9669 & 0,9378 & 0,9742 \\
\hline $\mathrm{jul} / 99$ & 0,9292 & 0,9842 & 0,9757 & 0,9909 & 0,9715 & 0,9881 & 0,9560 & 1,0072 \\
\hline ago/99 & 0,9972 & 1,0404 & 1,0474 & 1,0289 & 0,9988 & 1,0764 & 1,0044 & 1,1581 \\
\hline out/99 & 1,0032 & 1,0054 & 1,0258 & 0,9113 & 0,9659 & 1,0064 & 0,8932 & 1,0382 \\
\hline nov/99 & 0,9974 & 0,9986 & 0,9959 & 0,9725 & 0,9757 & 0,9811 & 0,9658 & 0,9837 \\
\hline dez/99 & 0,9988 & 0,9986 & 1,0055 & 0,9816 & 0,9711 & 0,9832 & 0,9359 & 0,9955 \\
\hline jan/00 & 0,9969 & 0,9967 & 0,9711 & 0,8436 & 0,9735 & 0,9885 & 0,6965 & 1,0089 \\
\hline fev/00 & 0,9864 & 1,0101 & 1,0322 & 1,1514 & 0,8011 & 1,0125 & 0,8915 & 1,2205 \\
\hline $\mathrm{mar} / 00$ & 1,0826 & 1,0652 & 1,0462 & 1,3586 & 0,8306 & 1,1205 & 1,0628 & 1,4867 \\
\hline $\mathrm{abr} / 00$ & 1,1277 & 1,0906 & 1,1492 & 1,0547 & 1,1065 & 1,1601 & 1,0252 & 1,1870 \\
\hline $\mathrm{mai} / 00$ & 0,9701 & 0,9884 & 0,9261 & 1,0152 & 0,9112 & 0,9832 & 0,9125 & 1,0401 \\
\hline jun $/ 00$ & 0,9407 & 0,9701 & 0,9155 & 0,9845 & 0,8588 & 0,9662 & 0,9249 & 1,0422 \\
\hline $\mathrm{jul} / 00$ & 0,9961 & 1,0064 & 1,0126 & 1,0310 & 0,8990 & 0,9884 & 0,9515 & 1,0603 \\
\hline ago/00 & 0,9993 & 0,9992 & 1,0139 & 0,8363 & 1,0037 & 1,0091 & 0,8635 & 1,0069 \\
\hline set/00 & 0,9661 & 0,9816 & 0,9594 & 0,9458 & 0,9608 & 0,9765 & 0,9450 & 0,9860 \\
\hline out $/ 00$ & 0,9975 & 0,9989 & 1,0521 & 0,7572 & 0,9736 & 0,9736 & 0,7438 & 0,9633 \\
\hline nov $/ 00$ & 0,9794 & 0,9870 & 0,9798 & 0,8710 & 0,8762 & 0,9841 & 0,7246 & 1,1238 \\
\hline $\operatorname{dez} / 00$ & 1,0018 & 0,9985 & 0,9838 & 1,0129 & 0,9940 & 1,0126 & 0,9961 & 1,0318 \\
\hline jan/01 & 1,0378 & 1,0191 & 1,0417 & 1,4675 & 0,7269 & 1,0242 & 0,8999 & 1,5002 \\
\hline fev/01 & 1,0561 & 1,0636 & 1,0461 & 0,9813 & 0,9544 & 1,1336 & 0,8885 & 1,1878 \\
\hline $\mathrm{mar} / 01$ & 1,2093 & 1,1353 & 1,1840 & 1,2380 & 1,0788 & 1,3283 & 1,0578 & 1,5120 \\
\hline $\mathrm{abr} / 01$ & 1,0370 & 1,0261 & 1,0161 & 0,8806 & 0,9564 & 1,0329 & 0,8608 & 1,0773 \\
\hline ago/01 & 1,0452 & 1,0294 & 1,0133 & 1,0669 & 0,9308 & 1,0556 & 1,0221 & 1,2050 \\
\hline set/01 & 0,9768 & 0,9846 & 1,0068 & 0,9337 & 0,9572 & 0,9636 & 0,8396 & 0,9710 \\
\hline out/01 & 0,9335 & 0,9708 & 0,9293 & 0,8865 & 0,8861 & 0,9312 & 0,8554 & 0,9607 \\
\hline nov $/ 01$ & 1,0031 & 0,9932 & 0,9219 & 0,9349 & 0,9886 & 0,9978 & 0,8558 & 1,0132 \\
\hline $\mathrm{dez} / 01$ & 0,9992 & 1,0195 & 1,0717 & 0,9549 & 0,7967 & 1,0798 & 0,9155 & 1,2915 \\
\hline $\mathrm{jan} / 02$ & 1,0114 & 1,0051 & 1,0313 & 1,1826 & 0,9621 & 1,0467 & 0,9822 & 1,0922 \\
\hline fev/02 & 1,0377 & 1,0411 & 1,0284 & 1,1864 & 0,9078 & 1,0654 & 1,0281 & 1,1984 \\
\hline $\mathrm{mar} / 02$ & 1,0983 & 1,0873 & 1,0787 & 1,1520 & 1,0005 & 1,1402 & 1,0492 & 1,2459 \\
\hline umulado & $1,7248$. & $1,9219$. & . 1,7438. & 2,1221. & 0,0451 . & 3,1939 . & 0,0315 . & 101,7902 \\
\hline
\end{tabular}

Fonte: Gameiro (2003). 
Tabela 4A_ Índices de fretes rodoviários mensais para a soja a granel de fevereiro de 1998 a março de 2002.

Tratamento 2: bases encadeadas

\begin{tabular}{|c|c|c|c|c|c|c|c|c|}
\hline Hipótese & Fisher & Eliminação & Suposição & Eliminação & Suposição & Walsh & Eliminação & Suposição \\
\hline $\mathrm{mar} / 98$ & 1,2216 & 1,1276 & 1,0899 & 1,1214 & 1,1214 & 1,1400 & 1,1199 & 1,0831 \\
\hline $\mathrm{abr} / 98$ & 0,9939 & 1,0587 & 1,0348 & 1,0379 & 1,0379 & 1,0406 & 1,0514 & 1,0302 \\
\hline $\mathrm{mai} / 98$ & 0,9989 & 0,9154 & 0,9366 & 0,9315 & 0,9252 & 0,9261 & 0,9063 & 0,9278 \\
\hline jun $/ 98$ & 1,0534 & 1,0412 & 1,0313 & 1,0286 & 1,0353 & 1,0424 & 1,0378 & 1,0279 \\
\hline $\mathrm{jul} / 98$ & 1,0063 & 0,9988 & 0,9905 & 0,9968 & 0,9939 & 0,9976 & 0,9963 & 0,9871 \\
\hline $\mathrm{ago} / 98$ & 0,9740 & 0,9914 & 0,9938 & 1,0096 & 1,0023 & 1,0046 & 0,9842 & 0,9887 \\
\hline set $/ 98$ & 0,9620 & 0,9964 & 0,9952 & 0,9755 & 0,9795 & 0,9780 & 0,9925 & 0,9925 \\
\hline out $/ 98$ & 0,9059 & 0,9405 & 0,9445 & 0,9466 & 0,9302 & 0,9250 & 0,9264 & 0,9398 \\
\hline nov/98 & 0,9000 & 0,9556 & 0,9694 & 0,9494 & 0,9479 & 0,9422 & 0,9477 & 0,9672 \\
\hline $\mathrm{dez} / 98$ & 0,9534 & 0,9654 & 0,9801 & 0,9540 & 0,9530 & 0,9533 & 0,9594 & 0,9772 \\
\hline jan/99 & 1,0056 & 1,0062 & 1,0037 & 1,0086 & 1,0077 & 1,0081 & 1,0042 & 1,0024 \\
\hline fev/99 & 1,2889 & 1,1040 & 1,0913 & 1,1195 & 1,1309 & 1,1456 & 1,0938 & 1,0829 \\
\hline $\mathrm{mar} / 99$ & 1,0966 & 1,0950 & 1,0826 & 1,0760 & 1,0811 & 1,0897 & 1,0883 & 1,0752 \\
\hline abr/99 & 1,0443 & 1,0579 & 1,0546 & 1,0245 & 1,0324 & 1,0624 & 1,0638 & 1,0466 \\
\hline mai/99 & 0,9264 & 0,9276 & 0,9490 & 0,9342 & 0,9274 & 0,9266 & 0,9289 & 0,9454 \\
\hline jun/99 & 0,9558 & 0,9768 & 0,9816 & 0,9620 & 0,9601 & 0,9619 & 0,9733 & 0,9799 \\
\hline jul/99 & 0,9813 & 0,9827 & 0,9815 & 0,9847 & 0,9844 & 0,9869 & 0,9788 & 0,9782 \\
\hline ago/99 & 1,0785 & 1,0549 & 1,0381 & 1,0542 & 1,0575 & 1,0677 & 1,0550 & 1,0359 \\
\hline out $/ 99$ & 0,9630 & 1,0018 & 1,0043 & 1,0048 & 1,0056 & 1,0033 & 1,0007 & 1,0032 \\
\hline nov/99 & 0,9747 & 0,9947 & 0,9971 & 0,9841 & 0,9794 & 0,9794 & 0,9920 & 0,9958 \\
\hline todez/99 & 0,9652 & 0,9974 & 0,9978 & 0,9888 & 0,9866 & 0,9843 & 0,9956 & 0,9970 \\
\hline $\mathrm{jan} / 00$ & 0,8383 & 0,9972 & 0,9964 & 0,9969 & 0,9993 & 0,9943 & 0,9962 & 0,9960 \\
\hline fev $/ 00$ & 1,0431 & 0,9866 & 1,0079 & 0,9885 & 0,9788 & 0,9827 & 0,9833 & 1,0060 \\
\hline $\mathrm{mar} / 00$ & 1,2570 & 1,0757 & 1,0548 & 1,0742 & 1,0788 & 1,0940 & 1,0731 & 1,0460 \\
\hline abr/00 & 1,1031 & 1,1009 & 1,0811 & 1,0989 & 1,1181 & 1,1383 & 1,1179 & 1,0735 \\
\hline mai/00 & 0,9742 & 0,9671 & 0,9842 & 0,9865 & 0,9731 & 0,9728 & 0,9583 & 0,9797 \\
\hline jun $/ 00$ & 0,9818 & 0,9387 & 0,9630 & 0,9559 & 0,9425 & 0,9433 & 0,9292 & 0,9552 \\
\hline $\mathrm{jul} / 00$ & 1,0044 & 0,9941 & 1,0023 & 0,9912 & 0,9913 & 0,9847 & 0,9915 & 0,9983 \\
\hline $\mathrm{ago} / 00$ & 0,9324 & 0,9962 & 0,9969 & 1,0047 & 1,0076 & 1,0059 & 0,9915 & 0,9945 \\
\hline set $/ 00$ & 0,9653 & 0,9620 & 0,9777 & 0,9767 & 0,9714 & 0,9742 & 0,9516 & 0,9724 \\
\hline out $/ 00$ & 0,8465 & 0,9918 & 0,9955 & 0,9901 & 0,9725 & 0,9660 & 0,9822 & 0,9922 \\
\hline nov $/ 00$ & 0,9024 & 0,9790 & 0,9843 & 1,0065 & 0,9950 & 0,9954 & 0,9704 & 0,9812 \\
\hline $\mathrm{dez} / 00$ & 1,0138 & 0,9991 & 0,9974 & 1,0111 & 1,0116 & 1,0123 & 0,9963 & 0,9961 \\
\hline $\mathrm{jan} / 01$ & 1,1619 & 1,0256 & 1,0143 & 1,0164 & 1,0206 & 1,0320 & 1,0237 & 1,0101 \\
\hline $\mathrm{fev} / 01$ & 1,0273 & 1,0387 & 1,0489 & 1,0319 & 1,0321 & 1,0512 & 1,0396 & 1,0386 \\
\hline $\mathrm{mar} / 01$ & 1,2646 & 1,1658 & 1,1166 & 1,1707 & 1,1844 & 1,2482 & 1,1823 & 1,1016 \\
\hline $\mathrm{abr} / 01$ & 0,9630 & 1,0233 & 1,0208 & 1,0066 & 1,0029 & 1,0071 & 1,0229 & 1,0165 \\
\hline $\mathrm{ago} / 01$ & 1,1098 & 1,0413 & 1,0255 & 1,0462 & 1,0531 & 1,0570 & 1,0422 & 1,0217 \\
\hline set/01 & 0,9029 & 0,9780 & 0,9829 & 0,9751 & 0,9693 & 0,9642 & 0,9725 & 0,9809 \\
\hline out/01 & 0,9065 & 0,9357 & 0,9683 & 0,9230 & 0,9142 & 0,9165 & 0,9274 & 0,9655 \\
\hline nov/01 & 0,9312 & 0,9997 & 0,9894 & 0,9942 & 0,9943 & 0,9973 & 0,9961 & 0,9843 \\
\hline $\mathrm{dez} / 01$ & 1,0874 & 0,9968 & 1,0136 & 0,9941 & 0,9960 & 1,0039 & 0,9933 & 1,0089 \\
\hline jan $/ 02$ & 1,0358 & 1,0063 & 1,0006 & 1,0278 & 1,0141 & 1,0195 & 1,0025 & 0,9963 \\
\hline $\mathrm{fev} / 02$ & 1,1100 & 1,0281 & 1,0339 & 1,0590 & 1,0407 & 1,0462 & 1,0216 & 1,0274 \\
\hline mar/02 & 1,1433 & 1,0857 & 1,0763 & 1,0590 & 1,0685 & 1,0905 & 1,0842 & 1,0674 \\
\hline Acumulado & 1,7893 & 1,5029 & 1,5490 & 1,4983 & 1,3482 & 1,7107 & 1,2411 & 1,2449 \\
\hline
\end{tabular}

Fonte: Gameiro (2003) 
Tabela 5A_ Índices de fretes rodoviários mensais para a soja a granel de fevereiro de 1998 a março de 2002. Tratamento 2: bases encadeadas

\begin{tabular}{|c|c|c|c|c|c|c|c|c|}
\hline Hipótese & Eliminação & Suposição & Eliminação & Suposição & Eliminação & Suposição & Ambas & Ambas \\
\hline $\mathrm{mar} / 98$ & 1,1331 & 1,1331 & 1,1374 & 1,1140 & 1,1272 & 1,1272 & 1,1242 & 1,1398 \\
\hline abr/98 & 1,0352 & 1,0352 & 1,2416 & 1,0348 & 1,0365 & 1,0365 & 1,0341 & 1,0409 \\
\hline jun $/ 98$ & 1,0504 & 1,0495 & 1,0333 & 1,0333 & 1,0428 & 1,0423 & 1,0416 & 1,0427 \\
\hline jul $/ 98$ & 1,0015 & 1,0002 & 1,0029 & 0,9924 & 0,9977 & 0,9970 & 0,9977 & 0,9976 \\
\hline ago/98 & 1,0052 & 1,0059 & 1,0724 & 1,0002 & 1,0037 & 1,0041 & 1,0040 & 1,0043 \\
\hline set $/ 98$ & 0,9784 & 0,9776 & 1,0245 & 0,9779 & 0,9789 & 0,9785 & 0,9791 & 0,9781 \\
\hline nov $/ 98$ & 0,9410 & 0,9410 & 1,0310 & 0,9461 & 0,9444 & 0,9444 & 0,9455 & 0,9421 \\
\hline $\mathrm{dez} / 98$ & 0,9544 & 0,9552 & 0,9568 & 0,9502 & 0,9537 & 0,9541 & 0,9540 & 0,9534 \\
\hline jan/99 & 1,0102 & 1,0102 & 1,0134 & 1,0060 & 1,0089 & 1,0089 & 1,0082 & 1,0084 \\
\hline fev/99 & 1,1275 & 1,1538 & 1,1222 & 1,1222 & 1,1292 & 1,1423 & 1,1258 & 1,1455 \\
\hline $\mathrm{mar} / 99$ & 1,1022 & 1,1033 & 1,0862 & 1,0779 & 1,0916 & 1,0921 & 1,0884 & 1,0907 \\
\hline abr/99 & 1,0806 & 1,0926 & 1,1341 & 1,0242 & 1,0562 & 1,0621 & 1,0545 & 1,0620 \\
\hline $\mathrm{mai} / 99$ & 0,9275 & 0,9277 & 0,9555 & 0,9257 & 0,9286 & 0,9275 & 0,9293 & 0,9265 \\
\hline jun $/ 99$ & 0,9661 & 0,9647 & 0,9810 & 0,9582 & 0,9631 & 0,9624 & 0,9630 & 0,9621 \\
\hline jul/99 & 0,9894 & 0,9863 & 1,0124 & 0,9826 & 0,9869 & 0,9853 & 0,9872 & 0,9868 \\
\hline ago/99 & 1,0697 & 1,0738 & 1,1207 & 1,0558 & 1,0636 & 1,0656 & 1,0624 & 1,0678 \\
\hline out $/ 99$ & 1,0013 & 1,0054 & 1,1337 & 1,0050 & 1,0035 & 1,0055 & 1,0031 & 1,0034 \\
\hline nov $/ 99$ & 0,9798 & 0,9798 & 0,9927 & 0,9781 & 0,9796 & 0,9796 & 0,9797 & 0,9794 \\
\hline $\mathrm{dez} / 99$ & 0,9835 & 0,9826 & 1,0386 & 0,9858 & 0,9850 & 0,9846 & 0,9849 & 0,9844 \\
\hline $\mathrm{jan} / 00$ & 0,9912 & 0,9878 & 1,4327 & 0,9989 & 0,9953 & 0,9935 & 0,9953 & 0,9943 \\
\hline $\mathrm{fev} / 00$ & 0,9909 & 1,0091 & 1,0702 & 0,9776 & 0,9848 & 0,9938 & 0,9852 & 0,9826 \\
\hline $\mathrm{mar} / 00$ & 1,0816 & 1,1090 & 1,0985 & 1,0749 & 1,0802 & 1,0938 & 1,0761 & 1,0939 \\
\hline $\mathrm{abr} / 00$ & 1,1401 & 1,1526 & 1,2491 & 1,1144 & 1,1290 & 1,1352 & 1,1268 & 1,1386 \\
\hline $\mathrm{mai} / 00$ & 0,9754 & 0,9792 & 1,0334 & 0,9691 & 0,9742 & 0,9761 & 0,9746 & 0,9727 \\
\hline jun $/ 00$ & 0,9517 & 0,9583 & 0,9574 & 0,9371 & 0,9471 & 0,9504 & 0,9480 & 0,9435 \\
\hline $\mathrm{jul} / 00$ & 0,9784 & 0,9838 & 1,0318 & 0,9893 & 0,9848 & 0,9875 & 0,9857 & 0,9844 \\
\hline ago/00 & 1,0052 & 1,0050 & 1,1794 & 1,0031 & 1,0064 & 1,0063 & 1,0055 & 1,0063 \\
\hline set $/ 00$ & 0,9738 & 0,9746 & 0,9958 & 0,9674 & 0,9726 & 0,9730 & 0,9746 & 0,9735 \\
\hline out $/ 00$ & 0,9683 & 0,9683 & 1,2506 & 0,9668 & 0,9704 & 0,9704 & 0,9713 & 0,9659 \\
\hline nov $/ 00$ & 0,9935 & 0,9784 & 1,3606 & 0,9920 & 0,9942 & 0,9867 & 0,9953 & 0,9946 \\
\hline $\mathrm{dez} / 00$ & 1,0125 & 1,0105 & 1,0276 & 1,0093 & 1,0120 & 1,0110 & 1,0120 & 1,0123 \\
\hline $\mathrm{jan} / 01$ & 1,0304 & 1,0179 & 1,1646 & 1,0169 & 1,0255 & 1,0192 & 1,0244 & 1,0322 \\
\hline fev/01 & 1,0571 & 1,1079 & 1,2127 & 1,0274 & 1,0445 & 1,0693 & 1,0433 & 1,0512 \\
\hline $\mathrm{mar} / 01$ & 1,2257 & 1,3012 & 1,4054 & 1,1677 & 1,2049 & 1,2415 & 1,1982 & 1,2478 \\
\hline $\mathrm{abr} / 01$ & 1,0135 & 1,0248 & 1,1699 & 1,0000 & 1,0082 & 1,0138 & 1,0067 & 1,0077 \\
\hline ago/01 & 1,0516 & 1,0525 & 1,0889 & 1,0516 & 1,0524 & 1,0528 & 1,0520 & 1,0570 \\
\hline set/01 & 0,9645 & 0,9611 & 1,1083 & 0,9672 & 0,9669 & 0,9652 & 0,9673 & 0,9643 \\
\hline out $/ 01$ & 0,9258 & 0,9287 & 0,9655 & 0,9113 & 0,9200 & 0,9214 & 0,9210 & 0,9163 \\
\hline nov $/ 01$ & 1,0009 & 0,9939 & 1,1529 & 0,9920 & 0,9976 & 0,9941 & 0,9975 & 0,9973 \\
\hline $\mathrm{dez} / 01$ & 1,0110 & 1,0639 & 1,0829 & 0,9939 & 1,0035 & 1,0294 & 1,0033 & 1,0040 \\
\hline $\mathrm{jan} / 02$ & 1,0234 & 1,0360 & 1,0481 & 1,0086 & 1,0187 & 1,0250 & 1,0185 & 1,0196 \\
\hline $\mathrm{fev} / 02$ & 1,0373 & 1,0565 & 1,0550 & 1,0342 & 1,0390 & 1,0486 & 1,0405 & 1,0450 \\
\hline $\mathrm{mar} / 02$ & 1,1027 & 1,1287 & 1,0925 & 1,0640 & 1,0855 & 1,0982 & 1,0816 & 1,0909 \\
\hline Acumulado & 1,8283. & 2,4542 . & $59,9691$. & 1,1406. & 1,5719 & 1,8190 . & . 1,5478 . & 1,7063 \\
\hline
\end{tabular}

Fonte: Gameiro (2003). 
Tabela 6A_ Índices de fretes rodoviários mensais para a soja a granel de fevereiro de 1998 a março de 2002. Tratamento 3: bases encadeadas

\begin{tabular}{|c|c|c|c|c|c|}
\hline Mês & Eliminação & Dutot & Sem redistribuição dos pesos & Com redistribuição dos pesos & Eliminação \\
\hline $\mathrm{mar} / 98$ & 1,1083 & 1,1484 & 1,3995 & 1,0973 & 1,0858 \\
\hline $\mathrm{abr} / 98$ & 1,0254 & 0,9738 & 1,1171 & 1,0059 & 1,0012 \\
\hline $\mathrm{mai} / 98$ & 0,9079 & 0,9206 & 0,9036 & 0,9309 & 0,9405 \\
\hline jun $/ 98$ & 1,0375 & 1,0157 & 1,0018 & 1,0252 & 1,0235 \\
\hline $\mathrm{jul} / 98$ & 0,9890 & 0,9797 & 1,0438 & 0,9653 & 0,9682 \\
\hline ago/98 & 1,0223 & 1,0054 & 0,8928 & 1,0074 & 1,0073 \\
\hline set $/ 98$ & 0,9819 & 0,9920 & 0,9295 & 0,9707 & 0,9723 \\
\hline out $/ 98$ & 0,9260 & 0,9535 & 0,8453 & 0,9042 & 0,9097 \\
\hline nov $/ 98$ & 0,9691 & 1,0152 & 0,9208 & 0,9754 & 0,9771 \\
\hline $\operatorname{dez} / 98$ & 0,9881 & 1,0041 & 0,9761 & 1,0059 & 1,0058 \\
\hline jan/99 & 0,9996 & 0,9742 & 1,0305 & 0,9996 & 0,9996 \\
\hline fev/99 & 1,1346 & 1,0993 & 1,4120 & 1,1144 & 1,0982 \\
\hline $\mathrm{mar} / 99$ & 1,1111 & 1,1293 & 1,3061 & 1,1393 & 1,1276 \\
\hline $\mathrm{abr} / 99$ & 1,0479 & 1,0328 & 0,9077 & 1,0420 & 1,0350 \\
\hline $\mathrm{mai} / 99$ & 0,9508 & 0,9403 & 0,8282 & 0,9460 & 0,9500 \\
\hline jun/99 & 0,9762 & 0,9769 & 1,0447 & 0,9768 & 0,9775 \\
\hline jul/99 & 0,9892 & 0,9698 & 0,9598 & 0,9653 & 0,9687 \\
\hline ago/99 & 1,0408 & 1,0296 & 1,0565 & 1,0560 & 1,0503 \\
\hline out/99 & 1,0072 & 1,1013 & 1,2398 & 1,0032 & 1,0025 \\
\hline nov/99 & 0,9832 & 0,9505 & 0,8871 & 0,8813 & 0,8817 \\
\hline $\mathrm{dez} / 99$ & 1,0123 & 1,0326 & 0,9955 & 1,0721 & 1,0704 \\
\hline $\mathrm{jan} / 00$ & 0,9667 & 0,8976 & 0,8171 & 0,8195 & 0,8076 \\
\hline $\mathrm{fev} / 00$ & 0,9903 & 1,0210 & 1,0264 & 0,9863 & 0,9879 \\
\hline $\mathrm{mar} / 00$ & 1,1163 & 1,0340 & 1,6262 & 1,1537 & 1,1210 \\
\hline $\mathrm{abr} / 00$ & 1,0930 & 1,1071 & 1,1227 & 1,1165 & 1,1056 \\
\hline $\begin{array}{l}\mathrm{mai} / 00 \\
\end{array}$ & 0,9705 & 0,9750 & 0,8192 & 0,9562 & 0,9609 \\
\hline jun $/ 00$ & 1,0144 & 0,9662 & 0,9860 & 0,9320 & 0,9379 \\
\hline $\mathrm{jul} / 00$ & 0,9879 & 0,9319 & 1,0241 & 0,9887 & 0,9897 \\
\hline ago/00 & 0,9987 & 0,9965 & 0,7955 & 0,9928 & 0,9941 \\
\hline set $/ 00$ & 0,9804 & 0,9561 & 0,9414 & 0,9536 & 0,9555 \\
\hline out $/ 00$ & 0,9931 & 1,0276 & 0,8265 & 0,9745 & 0,9775 \\
\hline nov $/ 00$ & 0,9955 & 0,9855 & 0,8494 & 1,0674 & 1,0636 \\
\hline $\mathrm{dez} / 00$ & 1,0060 & 0,9618 & 0,8189 & 0,9619 & 0,9654 \\
\hline $\mathrm{jan} / 01$ & 1,0118 & 1,0499 & 1,8388 & 1,0178 & 1,0100 \\
\hline $\mathrm{fev} / 01$ & 1,0632 & 1,0597 & 1,0607 & 1,0744 & 1,0663 \\
\hline $\mathrm{mar} / 01$ & 1,2231 & 1,2746 & 1,5427 & 1,2643 & 1,2002 \\
\hline $\mathrm{abr} / 01$ & 1,0133 & 0,9956 & 0,9372 & 0,9900 & 0,9910 \\
\hline ago/01 & 1,0505 & 1,0301 & 1,2206 & 1,0636 & 1,0540 \\
\hline set $/ 01$ & 0,9797 & 0,9753 & 0,8927 & 0,9547 & 0,9565 \\
\hline out/01 & 0,9887 & 1,0005 & 1,0290 & 1,0636 & 1,0709 \\
\hline nov $/ 01$ & 1,0003 & 0,9267 & 0,8639 & 1,0033 & 1,0031 \\
\hline $\mathrm{dez} / 01$ & 1,0040 & 1,0505 & 0,9677 & 0,9916 & 0,9932 \\
\hline jan $/ 02$ & 1,0233 & 1,0357 & 0,9691 & 1,0152 & 1,0139 \\
\hline $\mathrm{fev} / 02$ & 1,0526 & 1,0229 & 1,1157 & 1,0583 & 1,0554 \\
\hline $\mathrm{mar} / 02$ & 1,0558 & 1,0800 & 1,2284 & 1,0529 & 1,0445 \\
\hline umulado & 2,0982. & 1,6820. & 2,8722 & 1,4843 & 1,3086 \\
\hline
\end{tabular}

Fonte: Gameiro (2003). 
Tabela 7A_ Índices de fretes rodoviários mensais para a soja a granel de fevereiro de 1998 a março de 2002. Tratamento 4: bases encadeadas

\begin{tabular}{|c|c|c|c|c|c|}
\hline Mês & (MOD) & (Sifreca) & $\begin{array}{l}\text { Tornquist } \\
\text { (MOD) }\end{array}$ & $\begin{array}{l}\text { Theil } \\
\text { (MOD) }\end{array}$ & $\begin{array}{c}\text { Vartia II } \\
\text { (MOD) }\end{array}$ \\
\hline $\mathrm{mar} / 98$ & 1,2077 & 1,2038 & 1,2096 & 1,2096 & 1,2096 \\
\hline $\mathrm{abr} / 98$ & 0,9913 & 0,9838 & 0,9953 & 0,9953 & 0,9953 \\
\hline mai/98 & 0,9233 & 0,9181 & 0,9264 & 0,9264 & 0,9264 \\
\hline jun $/ 98$ & 1,0310 & 1,0198 & 1,0384 & 1,0384 & 1,0384 \\
\hline jul/98 & 1,0100 & 1,0113 & 1,0090 & 1,0090 & 1,0090 \\
\hline ago/98 & 1,0226 & 1,0177 & 1,0263 & 1,0263 & 1,0263 \\
\hline set $/ 98$ & 1,0043 & 1,0029 & 1,0054 & 1,0054 & 1,0054 \\
\hline out $/ 98$ & 0,9353 & 0,9255 & 0,9432 & 0,9432 & 0,9432 \\
\hline $\mathrm{dez} / 98$ & 0,9780 & 0,9997 & 0,9624 & 0,9624 & 0,9623 \\
\hline $\mathrm{jan} / 99$ & 1,0146 & 1,0174 & 1,0132 & 1,0132 & 1,0132 \\
\hline fev/99 & 1,1320 & 1,1382 & 1,1290 & 1,1290 & 1,1290 \\
\hline $\mathrm{mar} / 99$ & 1,0701 & 1,0610 & 1,0738 & 1,0738 & 1,0738 \\
\hline $\mathrm{abr} / 99$ & 1,0491 & 1,0438 & 1,0518 & 1,0518 & 1,0518 \\
\hline mai/99 & 0,9189 & 0,9229 & 0,9167 & 0,9167 & 0,9167 \\
\hline jun/99 & 0,9577 & 0,9625 & 0,9553 & 0,9553 & 0,9553 \\
\hline jul/99 & 1,0172 & 1,0223 & 1,0149 & 1,0149 & 1,0149 \\
\hline ago/99 & 1,0509 & 1,0404 & 1,0552 & 1,0552 & 1,0552 \\
\hline nov $/ 99$ & 0,9825 & 0,9712 & 0,9888 & 0,9888 & 0,9888 \\
\hline $\mathrm{dez} / 99$ & 1,0688 & 1,0750 & 1,0646 & 1,0646 & 1,0646 \\
\hline $\mathrm{jan} / 00$ & 0,9777 & 0,9404 & 1,0006 & 1,0006 & 1,0006 \\
\hline $\mathrm{fev} / 00$ & 0,9913 & 1,0092 & 0,9736 & 0,9736 & 0,9736 \\
\hline $\mathrm{mar} / 00$ & 1,0453 & 1,0546 & 1,0377 & 1,0377 & 1,0377 \\
\hline $\mathrm{abr} / 00$ & 1,0836 & 1,0854 & 1,0822 & 1,0822 & 1,0822 \\
\hline $\mathrm{mai} / 00$ & 0,9747 & 0,9833 & 0,9687 & 0,9687 & 0,9687 \\
\hline jun $/ 00$ & 0,9448 & 0,9517 & 0,9406 & 0,9406 & 0,9406 \\
\hline $\mathrm{jul} / 00$ & 1,0225 & 1,0232 & 1,0221 & 1,0221 & 1,0221 \\
\hline ago/00 & 0,9515 & 0,9413 & 0,9570 & 0,9570 & 0,9570 \\
\hline set $/ 00$ & 1,0183 & 1,0253 & 1,0139 & 1,0139 & 1,0139 \\
\hline out $/ 00$ & 0,9519 & 0,9355 & 0,9613 & 0,9613 & 0,9613 \\
\hline nov $/ 00$ & 0,9788 & 0,9773 & 0,9800 & 0,9800 & 0,9800 \\
\hline $\mathrm{dez} / 00$ & 1,0075 & 1,0031 & 1,0108 & 1,0108 & 1,0108 \\
\hline $\mathrm{jan} / 01$ & 1,0712 & 1,0822 & 1,0624 & 1,0624 & 1,0624 \\
\hline $\mathrm{fev} / 01$ & 1,0411 & 1,0511 & 1,0341 & 1,0341 & 1,0341 \\
\hline $\mathrm{mar} / 01$ & 1,2349 & 1,2292 & 1,2384 & 1,2384 & 1,2384 \\
\hline $\mathrm{abr} / 01$ & 0,9669 & 0,9543 & 0,9751 & 0,9751 & 0,9751 \\
\hline mai/01 & 0,8905 & 0,8890 & 0,8916 & 0,8916 & 0,8916 \\
\hline ago/01 & 1,0346 & 1,0372 & 1,0329 & 1,0329 & 1,0329 \\
\hline set/01 & 0,9715 & 0,9698 & 0,9725 & 0,9725 & 0,9725 \\
\hline out $/ 01$ & 0,9240 & 0,9166 & 0,9286 & 0,9286 & 0,9286 \\
\hline nov/01 & 1,0442 & 1,0694 & 1,0264 & 1,0264 & 1,0264 \\
\hline $\mathrm{dez} / 01$ & 1,0388 & 1,0384 & 1,0391 & 1,0391 & 1,0391 \\
\hline $\mathrm{jan} / 02$ & 1,0065 & 1,0147 & 1,0026 & 1,0026 & 1,0026 \\
\hline $\mathrm{fev} / 02$ & 1,0409 & 1,0430 & 1,0401 & 1,0401 & 1,0401 \\
\hline $\mathrm{mar} / 02$ & 1,0562 & 1,0447 & 1,0605 & 1,0605 & 1,0605 \\
\hline Acumulado & 1,7838 & 1,7670 & 1,7610 & 1,7610 & 1,7610 . \\
\hline
\end{tabular}

Fonte: Gameiro (2003) 